\title{
The Estimation of Air
}

Concentrations Due to the

Suspension of Surface

Contamination by the Wind

by

Thomas W. Horst

March 1976

Prepared for the Atlantic Richfield Hanford

Company and the U.S. Energy Research and

Development Administration under

Contracts E(45-1)-2130 and E(45-1)-1830 
NOTICE

This report was prepared as an account of work sponsored by the United States Government. Neither the United States nor the Energy Research and Development Administration, nor any of their employees, nor any of their contractors, subcontractors, or their employees, makes any warranty, express or implied, or assumes any legal liability or responsibility for the accuracy, completeness or usefulness of any imformation, apparatus, product or process disciosed, or represents that its use would not infringe privately owned rights.

PACIFIC NORTHWEST LABORATORY

operated by

BATTELLE

for the

ENERGY RESEARCH AND DEVELOPMENT ADMINISTRATION

Under Contract E(45-1)-1830

Printed in the United States of America

Available from

National Technical information Service

U.S. Department of Commerce

5285 Port Royal Road

Springfield, Virginia 2215

Price: Printed Copy 55.00; Microfiche $\$ 2.25$ 
THE ESTIMATION OF AIR CONCENTRATIONS DUE TO THE SUSPENSION OF SURFACE

CONTAMINATION BY THE WIND

by

Thomas W. Horst

Atmospheric Sciences Department

March 1976

Battelle

Pacific Northwest Laboratories

Richland, Washington 99352 


\section{$\underline{\text { ABSTRACT }}$}

A mathematical model is developed for the calculation of air concentrations of material suspended by the wind from areas of surface contamination and the model is applied specifically to the BC Controlled Area. Excomple computer solutions are given to show the dependence of the suspended air concentration on suspension rate, deposition velocity, wind speed, wind direction and atmospheric stability.

This model is subsequently simplified to produce an analytical method for the economical estimation of air concentrations and horizontal fluxes of suspended surface contamination. The predictions of the analytical method are demonstrated to agree quite well with those of the more complex, computerized model. 
List of figures. . . . . . . . . . . . . . . . . . . vi

List of Tables. . . . . . . . . . . . . . . . . vii

Introduction. . . . . . . . . . . . . . . . . . . 1

Summary and Conclusions . . . . . . . . . . . . . . . . 1

The Surface Flux Model. . . . . . . . . . . . . . . . . 3

Model Derivation . . . . . . . . . . . . . . . 3

Predicted Air Concentrations for the
BC Controlled Area . . . . . . . . . . . . . . . 5

A Simplified Prediction Method. . . . . . . . . . . . . . 19

Model Derivation .. . . . . . . . . . . . 19

Comparison with the Exact Solution . . . . . . . . . . . 24

Extension to the Crosswind Distribution. . . . . . . . . 26

Calculation of the Horizontal Flux . . . . . . . . . . 32

Usefulness of the Resuspension Factor. . . . . . . . . . 37

Acknowledgments . . . . . . . . . . . . . . . . . 39

References. . . . . . . . . . . . . . . . . 41 
FIGURES

1 Contours of Cs-137 Surface Contamination in the

BC Controlled Area . . . . . . . . . . . . . . . 7

2 Contours of Normalized Suspended Air Concentration

$\mathrm{uC} / \Lambda$ in the $\mathrm{BC}$ Controlled Area for Pasquill A,

$\mathrm{v}_{\mathrm{d}} / \mathrm{u}=0$, and a West Wind. . . . . . . . . . . . . . . 9

3 Contours of Normalized Suspended Air Concentration

$\mathrm{uC} / \Lambda$ in the $\mathrm{BC}$ Controlled Area for Pasquill D,

$\mathrm{v}_{\mathrm{d}} / \mathrm{u}=0$, and a West Wind. . . . . . . . . . . . . . . . 10

4 Contours of Normalized Suspended Air Concentration $\mathrm{uC} / \Lambda$ in the $\mathrm{BC}$ Controlled Area for Pasquill $\mathrm{F}$, $\mathrm{v}_{\mathrm{d}} / \mathrm{u}=0$, and a West Wind. . . . . . . . . . . . . . . . 11

5 Contours of Normalized Suspended Air Concentration $\mathrm{uC} / \Lambda$ in the $\mathrm{BC}$ Controlled Area for Pasquill. D, $\mathrm{v}_{\mathrm{d}} / \mathrm{u}=10^{-3}$, and a West Wind ................

6 Contours of Normalized Suspended Air Concentration $\mathrm{uC} / \Lambda$ in the $\mathrm{BC}$ Controlled Area for Pasquill D, $\mathrm{v}_{\mathrm{d}} / \mathrm{u}=10^{-2}$, and a West Wind... . . . . . . . . . . .

7 Contours of Normalized Suspended Air Concentration $\mathrm{uC} / \Lambda$ in the $\mathrm{BC}$ Controlled Area for Pasquill D, $\mathrm{v}_{\mathrm{d}} / \mathrm{u}=10^{-1}$, and a West Wind . . . . . . . . . . . . . 14

8 Contours of Normalized Suspended Air Concentration $\mathrm{uC} / \Lambda$ in the $\mathrm{BC}$ Controlled Area for Pasquill D, $\mathrm{v}_{\mathrm{d}} / \mathrm{u}=0$, and a North Wind . . . . . . . . . . . . .

9 Contours of Normalized Suspended Air Concentration $\mathrm{uC} / \Lambda$ in the $\mathrm{BC}$ Controlled Area for Pasquill D, $\mathrm{v}_{\mathrm{d}} / \mathrm{u}=0$, and an East Wind ................

10 Contours of Normalized Suspended Air Concentration $\mathrm{uC} / \Lambda$ in the $\mathrm{BC}$ Controlled Area for Pasquill $\mathrm{D}$, $\mathrm{v}_{\mathrm{d}} / \mathrm{u}=0$, and a South Wind . . . . . . . . . . . . . .

11 Normalized Suspended Air Concentration $\mathrm{uC} / \Lambda \mathrm{G}$ for a

Uniform Area Source as a Function of Downwind

Distance . . . . . . . . . . . . . . . . . .

12 Comparison of Suspension-Deposition Models for a

Crosswind-Integrated Gaussian Area Source. . . . . . . . .

13 Comparison of Suspension-Deposition Models for the

Crosswind-Integrated BC Controlled Area. . . . . . . . . 
FIGURES (continued)

14 Comparison of Suspension Models for Gaussian Sources and Pasquill D Stability Category. . . . . . . . . . 28

15 Comparison of Suspension Models for Gaussian Sources and Pasquill F Stability Category. . . . . . . . . 30

16 Comparison of Suspension Models for Gaussian Sources and Pasquill A Stability Category. . . . . . . . . . 31

17 Comparison of Suspension-Deposition Models for the BC Controlled Area . . . . . . . . . . . . 33

18 Normalized Horizontal Flux $F_{H} / \Lambda G$ for a Uniform Area Source as a Function of Downwind Distance. . . . . . . . . . 35

19 Normalized Horizontal Flux $\mathrm{F}_{\mathrm{H}} / \Lambda$ for the $\mathrm{BC}$ Controlled Area . . . . . . . . . . . . . . . 36

\section{TABLES}

1 Formulas for the Determination of $\sigma_{z}$ and $\sigma_{y} \cdot \cdots \cdot \ldots$

2 Surface and Air Contamination Levels for

Figures 1-10... . . . . . . . . . . . . . 8 


\section{INTRODUCTION}

Radioactive contamination of environmental surfaces, such as exists in the BC Controlled Area, presents the potential for airborne contamination through the mechanism of suspension by the wind of the surface contamination. The amount of this derivative airborne contamination must be known in order to properly evaluate the consequences of various management and control policies which may be applied to the surface contamination. It is the intent of this report to provide a basis for predicting the air concentrations consequent to the suspension of surface contamination. This will be done by describing both complex and simple models which have been developed for this purpose and by presenting sample predictions of suspended air concentrations within the BC Controlled Area.

This report presents the results of research supported both by the Atlantic Richfield Hanford Company, under contract to the U.S. Energy Research and Development Administration, and by the Department of Biomedical and Environmental Research of the U.S. Energy Research and Development Administration.

\section{SUMMARY AND CONCLUSIONS}

A surface flux model is developed which can predict the air concentrations consequent to suspension by the wind of radioactive surface contamination. This model treats the suspension of the contamination and its redeposition on the surface as opposing processes whose net sum is the source term for subsequent atmospheric diffusion. Since the diffusion process is linear, existing point source diffusion models are used to describe the atmospheric transport from all points of the surface source, and the resultant air concentration is found by suming over the entire surface upwind of the receptor of interest. 
This model is applied to the prediction of suspended air concentrations within the $\mathrm{BC}$ Controlled Area for a limited number of cases. It is shown that these air concentrations are directly proportional to the suspension rate and inversely proportional to the mean wind speed and that the pattern of the air concentration isopleths is strongly dependent on wind direction. As also might be expected, the air concentrations decrease with increasing instability of the atmosphere and with increasing deposition. Similarly, the downwind elongation of the air concentration isopieths is reduced with increasing instability and deposition.

Some immediate applications of the model would be the estimation of the expected annual exposure within the BC Controlled Area and the annual flux of contamination out of the area. Predictions of the model should be compared to existing measurements of the airborne concentrations within the area, both to test and improve the model and also to estimate the rate of suspension and the fraction of the surface contamination available for suspension.

The exact computation of the suspended air concentration as described above is a tedious procedure because it requires the convolution of the areal source strength distribution with a point source function describing the atmospheric dilution of the suspended contamination. Therefore, a simplified procedure has also been developed from this basic model. It requires knowing only the total upwind surface contamination and the suspended air concentration predicted under similar meteorological conditions for the equivalent uniform contamination source without deposition. This method is shown to be quite accurate, both for a hypothetical regular distribution of surface contamination and for the BC Controlled Area. It has the potential of being very useful for the rapid, economicai estimation of both the air concentration and the horizontal flux due to the suspension of surface contamination.

Finally the usefulness of the resuspension factor (defined as the ratio of the suspended air concentration to the local ground contamination) for predicting suspended air concentrations is discussed. It is found that the resuspension factor has limited applicability downwind of a 
contaminated area. For practical estimates the resuspension factor may be treated as a constant with respect to receptor location within area sources which vary with a length scale exceeding several hundred meters. This assumption has the least error for unstable atmospheric conditions and high deposition.

\section{The Surface Flux Model}

\section{Model Derivation}

The differential equation describing the diffusion of atmospheric contaminants is linear in the calculated air concentration, allowing the superposition of solutions to account for a number of different pollutant sources at different locations. Thus the air concentration due to an areal source of contamination may be determined by integrating a point-source solution of the diffusion equation over the upwind extent of the area source distribution. To this end a diffusion function

$$
\mathrm{D}=\frac{\mathrm{uC} \text { p.s. }}{\dot{\mathrm{Q}}}=\frac{1}{\pi \sigma_{\mathrm{y} \sigma} \mathrm{z}} \exp \left(-\mathrm{y}^{2} / 2 \sigma_{\mathrm{y}}{ }^{2}-\mathrm{z}^{2} / 2 \sigma_{\mathrm{z}}{ }^{2}\right)
$$

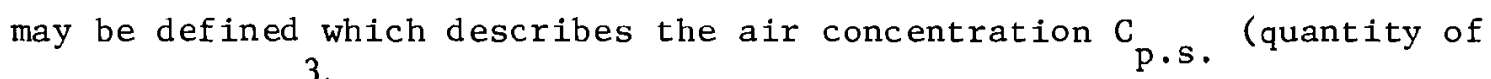
material per $\mathrm{m}^{3}$ ) due to a point source of nondepositing material located at ground level and emitting at a rate $\dot{Q}$ (quantity per sec). $C_{p . s}$. is evaluated at a height $z$ and at horizontal distances $x$ downwind and $y$ crosswind of the source; $u$ is the mean wind speed $(\mathrm{m} / \mathrm{sec})$, blowing in the positive $\mathrm{x}$ direction. $\mathrm{D}$ is described here by the Gaussian plume model ${ }^{(1)}$ parameterized by $\sigma_{y}$ and $\sigma_{z}$, the horizontal and vertical standard deviations ( $m$ ) of the concentration distribution. Given then the horizontal distribution of the net upward flux $\mathrm{F}_{\mathrm{z}}$ (quantity per $\mathrm{m}^{2} / \mathrm{sec}$ ) of contaminant at the surface, the air concentration is

$$
C(x, y, z)=\int_{0}^{x} \int_{-\infty}^{\infty} F_{z}(\xi, n) \frac{D}{u}(x-\xi, y-n, z) d n d \xi,
$$

where the origin of the $x$ coordinate is located at the upwind edge of the surface contamination. 
Two processes are assumed to contribute to the net interchange of material between the ground and the air: suspension and deposition. In the absence of detailed microphysical models of these processes, they will be described as being proportional to the ground contamination $G$ (quantity of material per $\mathrm{m}^{2}$ ) and the air concentration $\mathrm{C}$, respectively. Thus the vertical flux of material at the surface due to deposition is

$$
F_{d}=-v_{d} C\left(z=z_{d}\right)
$$

where $C$ is evaluated at some reference height $z_{d}$. The constant of proportionality $v_{d}$ has the dimensions of a velocity and has been appropriately named the deposition velocity. For common aerosols $v_{d}$ can vary from about $10^{-4}$ to $10 \mathrm{~cm} / \mathrm{sec}$, depending on the specific properties of the particles, of the atmospheric structure, and of the deposition surface. (2) The results presented here, however, are parameterized only by the ratio of the deposition velocity to the mean wind speed, $v_{d} / u$. Since $u$ in the lowest $100 \mathrm{~m}$ of the atmosphere is commonly in the range of $1-10 \mathrm{~m} / \mathrm{s}$, $\mathrm{v}_{\mathrm{d}} / \mathrm{u}$ can vary from about $10^{-7}$ to $10^{-1}$.

Similarly the resuspension $f 1 u x F_{r}$ is

$$
F_{r}=\Lambda G
$$

where $\Lambda$ is a suspension rate $\left(\mathrm{sec}^{-1}\right)$ and $G$ is the concentration of material on the ground that is available for suspension. Less is known about $\Lambda$ than about $v_{d}$ but typical values for Hanford soils appear to be in the range of $10^{-10}$ to $10^{-7} \mathrm{sec}^{-1}$. (3)

Thus the net vertical flux at the surface is

$$
F_{z}(x, y)=\Lambda G(x, y)-v_{d} C\left(x, y, z_{d}\right),
$$

and substitution of (5) into (2) gives

$$
C(x, y, z)=\int_{0}^{x} \int_{-\infty}^{\infty}\left[\Lambda G(\xi, \eta)-v_{d} C\left(\xi, \eta, z_{d}\right)\right] \frac{D}{u}(x-\xi, y-\eta, z) d \eta d \xi,
$$

the basic equation of the surface flux model. 
Predicted Air Concentrations for the BC Controlled Area

Since the calculation of suspended air concentrations requires in almost every case a numerical integration of (6), a FORTRAN program has been written to perform the necessary operations. This program currently uses the rural diffusion coefficients amalgamated by Briggs ${ }^{(4)}$ from several series of diffusion experiments. These are a function of the downwind distance $x$ separating source and receptor and of the turbulence intensity or stability of the atmosphere. Briggs' formulas are shown in Table 1 where the atmospheric stability is divided into six classes ranging from very unstable, Pasquill Class A, to neutral, Class D, to very stable, Class F. Class A is characteristically a clear day with low wind speed and strong insolation, Class D occurs with an overcast sky and/or strong winds, and Class $F$ is typically a clear nighttime situation with low winds.

By multiplying both sides of (6) by $u / \Lambda$, it can easily be seen that $\mathrm{uC} / \Lambda$ is a function only of $G, v_{d} / u$ and $D$ and thus that $C$ depends linearly on $\Lambda / u$. Given the horizontal distribution of the surface contamination $G$, a value for $v_{d} / u$ and a stability class, the FORTRAN program then calculates the horizontal distribution of the normalized air concentration $\mathrm{uC} / \Lambda$. The calculations are currently made on a 40 x 40 horizontal grid.

Table 1 .

Formulas for the Determination of $\sigma_{z}$ and $\sigma_{y}(4)$
\[ \left(x, \sigma_{z}, \sigma_{y} \text { in meters }\right) \]

Stability Class
A
B
C
$\mathrm{D}$
E
F
$0.20 \mathrm{x}$
$0.12 \mathrm{x}$
$0.08 x\left(1+2 * 10^{-4} x\right)^{-1 / 2}$
$0.06 x\left(1+1.5 * 10^{-3} x\right)^{-1 / 2}$
$0.03 x\left(1+3 * 10^{-4} x\right)^{-1}$
$0.02 x\left(1+3 * 10^{-4} x\right)^{-1}$

$\sigma_{z}$ y

$0.22 x\left(1+10^{-4} x\right)^{-1 / 2}$

$0.16 x\left(1+10^{-4} x\right)^{-1 / 2}$

$0.11 x\left(1+10^{-4} x\right)^{-1 / 2}$

$0.08 x\left(1+10^{-4} x\right)^{-1 / 2}$

$0.06 x\left(1+10^{-4} x\right)^{-1 / 2}$

$0.04 x\left(1+10^{-4} x\right)^{-1 / 2}$ 
These dimensions were chosen as a compromise between the conflicting requirements of spatial resolution and economy, recognizing that the evaluation of (6) is a tedious and hence expensive numerical process.

An aerial survey of the BC Controlled Area was performed (5) by EG\&G on May 30 and June 1, 1973, producing isopleths of $\mathrm{Cs}^{137}$ surface contamination within an area of roughly $15 \mathrm{~km}^{2}$. In order to provide the required input to the computational program, this distribution has been digitized at intervals of $100 \mathrm{~m}$, each data point equalling the surface contamination within an area of $10^{4} \mathrm{~m}^{2}$. Thus the following results assume that all of the surveyed contamination is available for suspension by the wind, while it is likely that only some fraction is truly available. However, if this fraction is constant over the distribution, the calculated air concentrations can simply be proportionally reduced.

Figure 1 shows the surface contamination distribution as reconstructed from the digitized data. The values of the labeled contours are 1isted in Table 2. The outlined central portion of the distribution, an area $2 \mathrm{~km}$ square, was selected as the source for the following sample calculations of suspended air concentrations. This choice allowed the use of a computational grid interval of $50 \mathrm{~m}$ and hence each digitized value of surface contamination was allotted to four grid points. Calculations were also made on an $80 \times 80,25 \mathrm{~m}$ grid to test the accuracy of the $40 \times 40,50 \mathrm{~m}$ computation and, except at the edges of the distribution, the results were found to agree within better than $5 \%$.

Figures 2-10, then, show the results of sample calculations of the suspended air concentrations at a height of $1 \mathrm{~m}, \mathrm{z}_{\mathrm{d}}$, for a variety of atmospheric stability conaitions, deposition velocities and wind directions. The quantity contoured is the normalized air concentration $u C / \Lambda$ and the values of the labeled contours are again listed in Table 2. (Note that the order of labeling is reversed from that of Figure 1.) Figure 3 for neutral stability, $v_{d} / u=0$ and a west wind (indicated by the $U$ arrow) may be considered the norm against which to compare the results for varying stability (Figures 2 and 4), $v_{d} / u$ (Figures 5-7) and wind direction (Figures 8-10). The air concentrations also vary linearly 


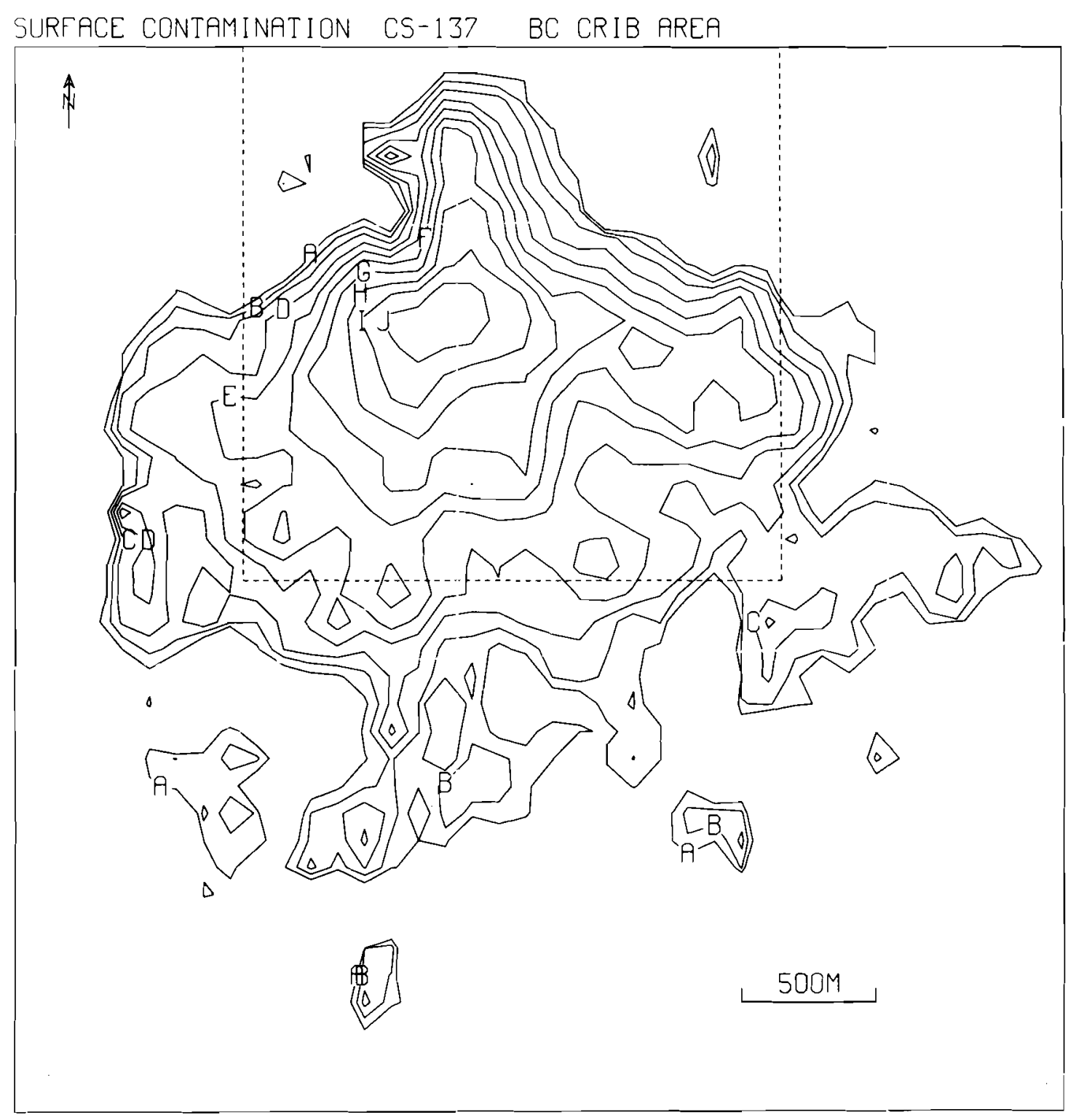

Figure 1. Contours of Cs-137 Surface Contamination in the BC Controlled Area 
Table 2 .

Surface and Air Contamination Levels for Figures 1-10

\begin{tabular}{lcccc}
\multicolumn{4}{l}{ Surface Contamination Levels, Figure 1} \\
\hline A & $0.12 \mu \mathrm{Ci} / \mathrm{m}^{2}$ & F & $0.88 \mu \mathrm{Ci} / \mathrm{m}^{2}$ \\
B & $0.18 \mu \mathrm{Ci} / \mathrm{m}^{2}$ & G & $1.33 \mu \mathrm{Ci} / \mathrm{m}^{2}$ \\
C & $0.26 \mu \mathrm{Ci} / \mathrm{m}^{2}$ & H & $2.0 \mu \mathrm{Ci} / \mathrm{m}^{2}$ \\
D & $0.40 \mu \mathrm{Ci} / \mathrm{m}^{2}$ & I & $3.0 \mu \mathrm{Ci} / \mathrm{m}^{2}$ \\
E & $0.59 \mu \mathrm{Ci} / \mathrm{m}^{2}$ & J & $4.5 \mu \mathrm{Ci} / \mathrm{m}^{2}$
\end{tabular}

Normalized Air Concentration Levels, Figures 2-10

$\begin{array}{lrlrlrl}\text { A } & 1000 \mu \mathrm{Ci} / \mathrm{m}^{2} & \mathrm{~F} & 100 \mu \mathrm{Ci} / \mathrm{m}^{2} & \mathrm{~K} & 10 \mu \mathrm{Ci} / \mathrm{m}^{2} \\ \mathrm{~B} & 630 \mu \mathrm{Ci} / \mathrm{m}^{2} & \mathrm{G} & 63 \mu \mathrm{Ci} / \mathrm{m}^{2} & \mathrm{~L} & 6.3 \mu \mathrm{Ci} / \mathrm{m}^{2} \\ \mathrm{C} & 400 \mu \mathrm{Ci} / \mathrm{m}^{2} & \mathrm{H} & 40 \mu \mathrm{Ci} / \mathrm{m}^{2} & \mathrm{M} & 4.0 \mu \mathrm{Ci} / \mathrm{m}^{2} \\ \mathrm{D} & 250 \mu \mathrm{Ci} / \mathrm{m}^{2} & \mathrm{I} & 25 \mu \mathrm{Ci} / \mathrm{m}^{2} & \mathrm{~N} & 2.5 \mu \mathrm{Ci} / \mathrm{m}^{2} \\ \mathrm{E} & 160 \mu \mathrm{Ci} / \mathrm{m}^{2} & \mathrm{~J} & 16 \mu \mathrm{Ci} / \mathrm{m}^{2} & \mathrm{O} & 1.6 \mu \mathrm{Ci} / \mathrm{m}^{2}\end{array}$

with wind speed and suspension rate, but this may be reproduced simply by multiplying the contour levels by the appropriate value of $\Lambda / u$. Recently measured (3) resuspension rates fall in the range $10^{-10}$ to $10^{-6} \mathrm{sec}^{-1}$ for surface wind speeds varying from $1-20 \mathrm{~m} / \mathrm{sec}$. An annual average value for $\Lambda / \mathrm{u}$ might be $10^{-9} \mathrm{~m}^{-1}$.

Figures 2-4 display the changes in suspended air concentration with atmospheric stability. The air concentrations are greatest for stable Pasquill $\mathrm{F}$ conditions and decrease with decreasing stability due to the enhanced effectiveness of the atmospheric eddies in mixing the suspended material with uncontaminated air. The peak concentration for Fasquiii A is approximately 20\% of that for Pasquill F. Further, the downwind elongation of the air concentration contours is greatest for Pasquill $\mathrm{F}$ for the same reason. At the east border of the computational area the air concentration for Pasquill A has dropped to $10 \%$ of that for Pasquill F.

Figures 3 and 5-7 display the effectiveness of deposition in reducing the air concentrations. The parameter controlling deposition is the ratio 
UC/A, RESUSPENSION FROM BC CRIB AREA. PASOUILL $A, \quad V D / U=0.0$

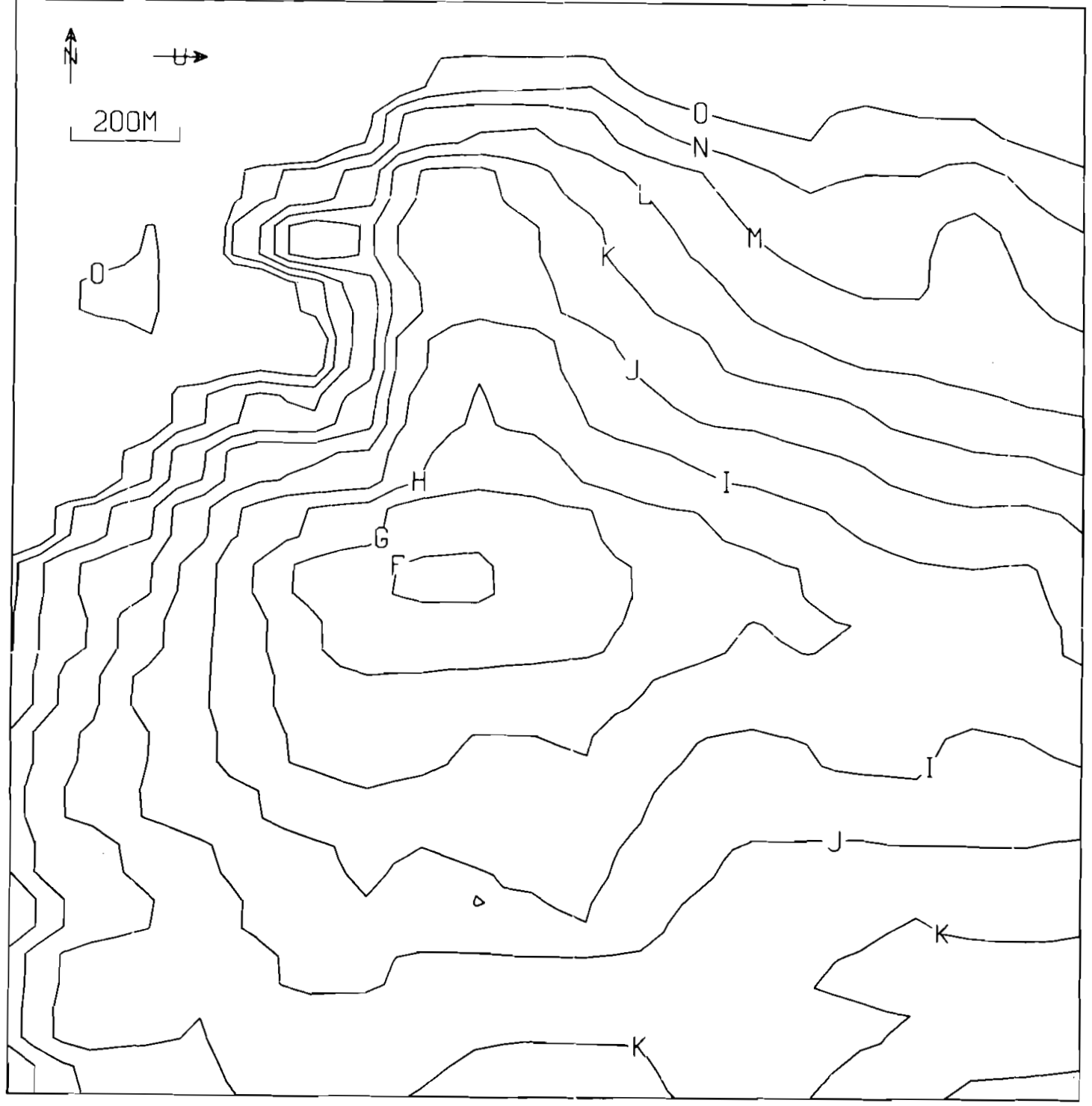

Figure 2. Contours of Normalized Suspended Air Concentration $\mathrm{uC} / \Lambda$ in the $\mathrm{BC}$ Controlled Area for Pasquill A, $\mathrm{v}_{\mathrm{d}} / \mathrm{u}=0$, and a West Wind 
$U C / \Lambda$, RESIJSPENSION FROM BC CRIB AREA. PASOUILL $D, V D / U=0.0$

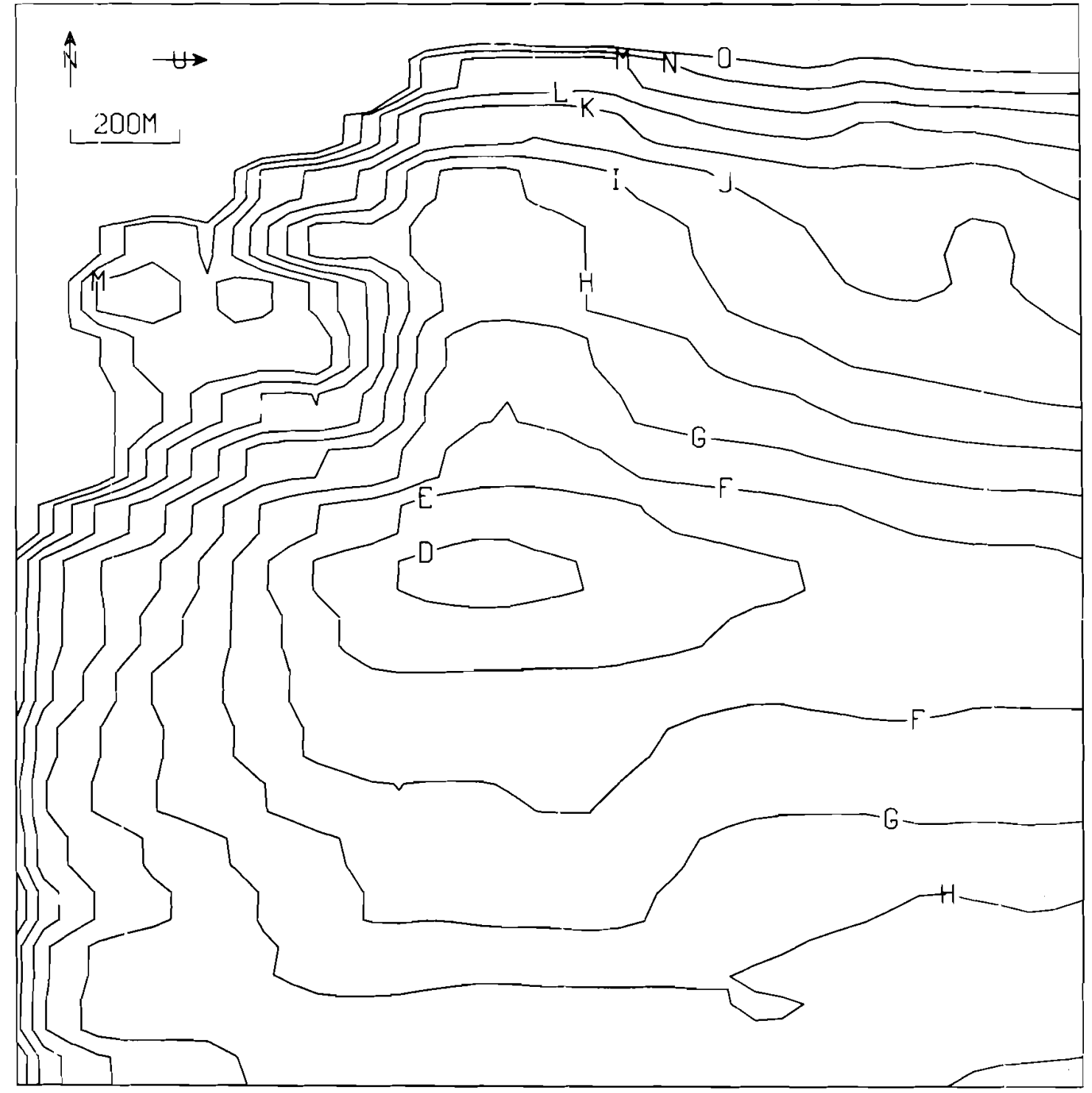

Figure 3. Contours of Normalized Suspended Air Concentration $\mathrm{uC} / \Lambda$ in the $\mathrm{BC}$ Controlled Area for Pasquill D, $v_{d} / u=0$, and a West wind 
UC/A, RESUSPENSION FROM BC CRIB AREA. PASQUILL F, VD/U $=0.0$

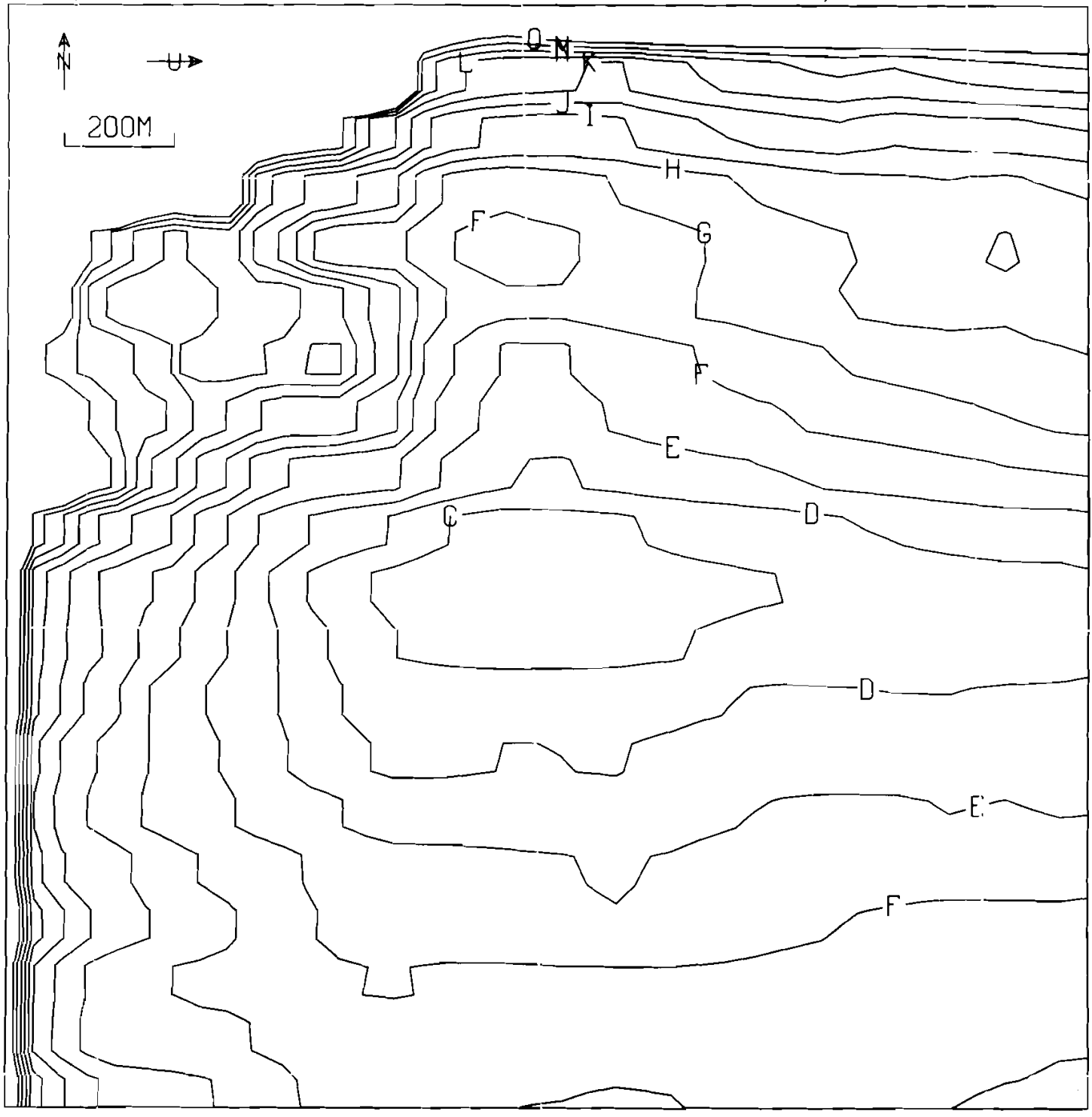

Figure 4. Contours of Normalized Suspended Air Concentration $\mathrm{uC} / \Lambda$ in the $\mathrm{BC}$ Controlled Area for Pasquill $\mathrm{F}$, $v_{d} / u=0$, and a West Wind 


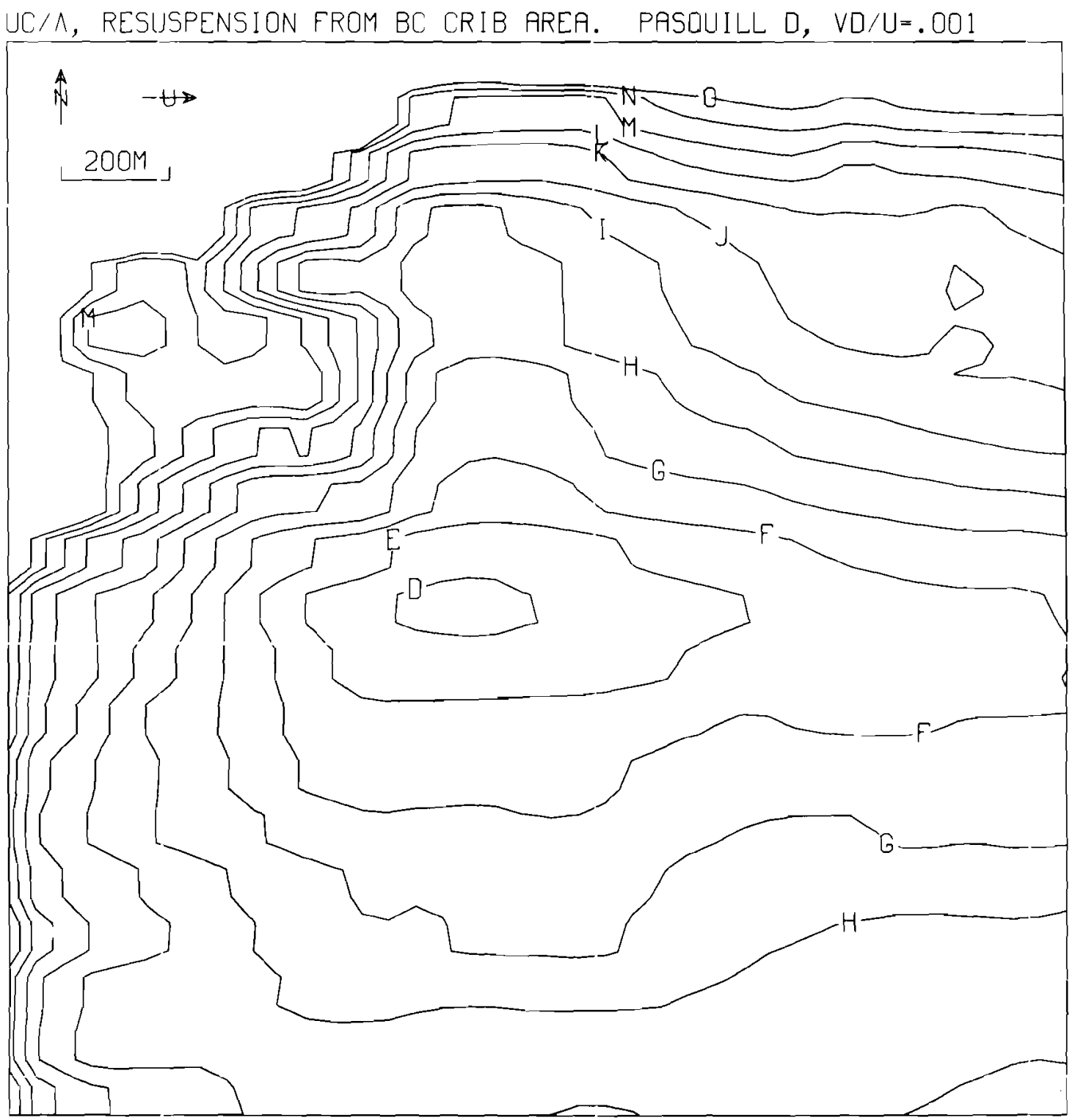

Figure 5. Contours of Normalized Suspended Air Concentration $\mathrm{uC} / \Lambda$ in the $\mathrm{BC}$ Controlled Area for Pasquill D, $\mathrm{v}_{\mathrm{d}} / \mathrm{u}=10^{-3}$, and a West wind 
$U C / \Lambda$, RESUSPENSION FROM BC CRIB RREA. PRSOUILL $D, V D / U=.01$

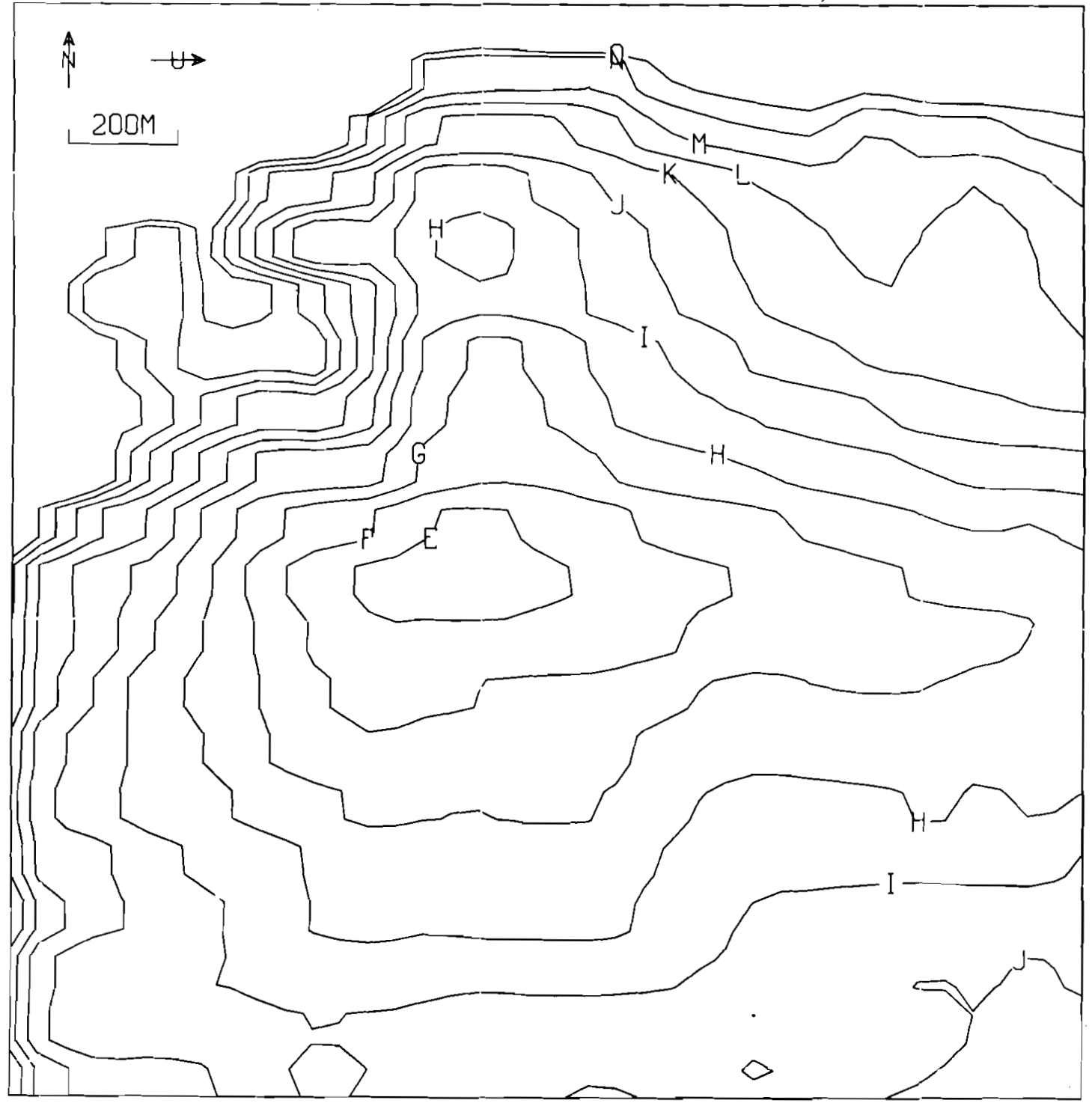

Figure 6. Contours of Normalized Suspended Air Concentration $\mathrm{uC} / \Lambda$ in the $\mathrm{BC}$ Controlled Area for Pasquill D, $v_{d} / u=10^{-2}$, and a West Wind 
UC $/ \wedge$, RESUSPENSION FROM BC CRIB AREA. PASOUILL D, VD/U-0.1

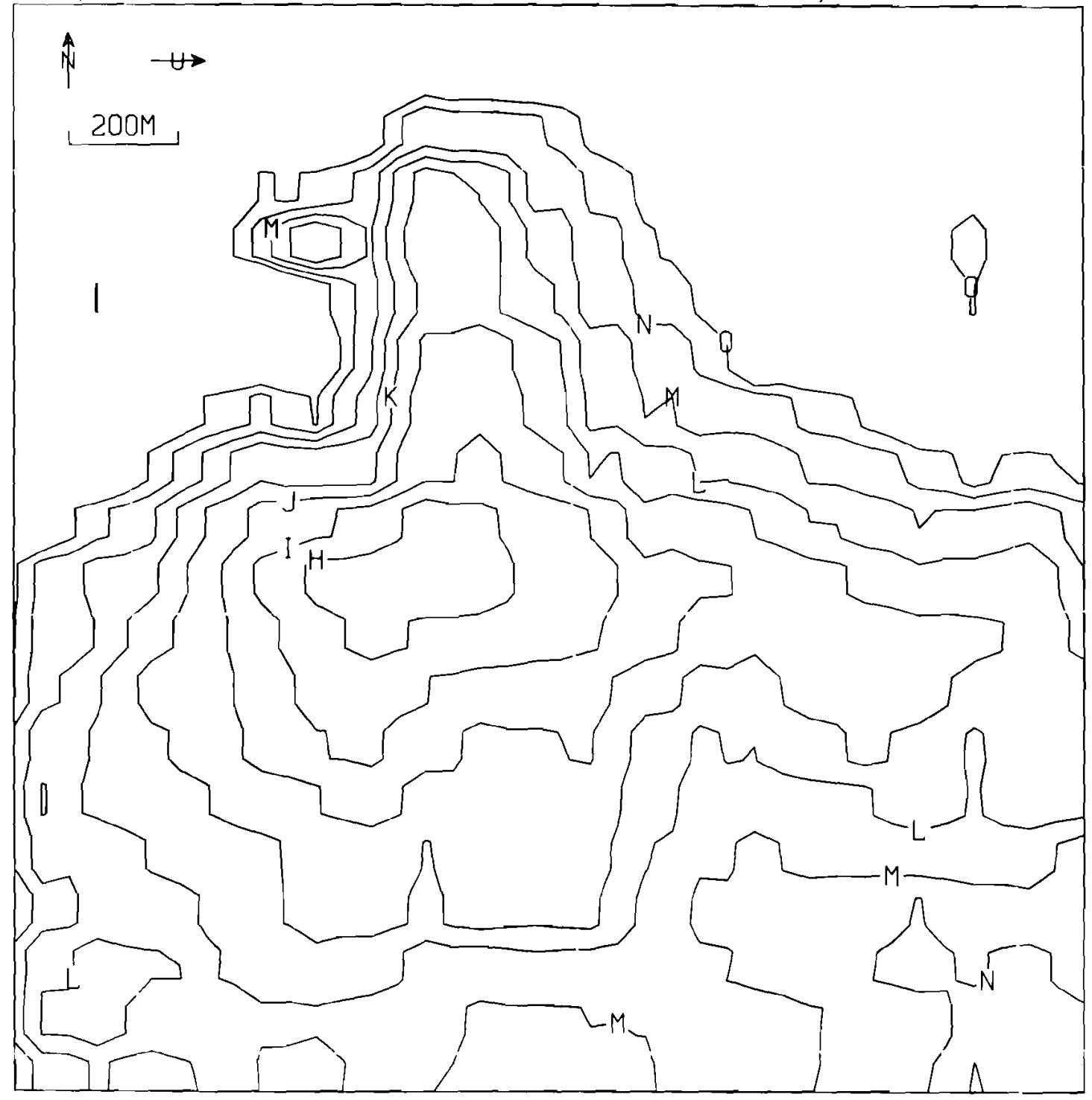

Figure 7. Contours of Normalized Suspended Air Concentration $\mathrm{uC} / \Lambda$ in the $\mathrm{BC}$ Controlled Area for Pasquill D, $\mathrm{v}_{\mathrm{d}} / \mathrm{u}=10^{-1}$, and $\mathrm{a}$ West Wind 
$U C / \Lambda$, RESUSPENSION FROM BC CRIB RREA. PASOUILL $D, V D / U=0.0$

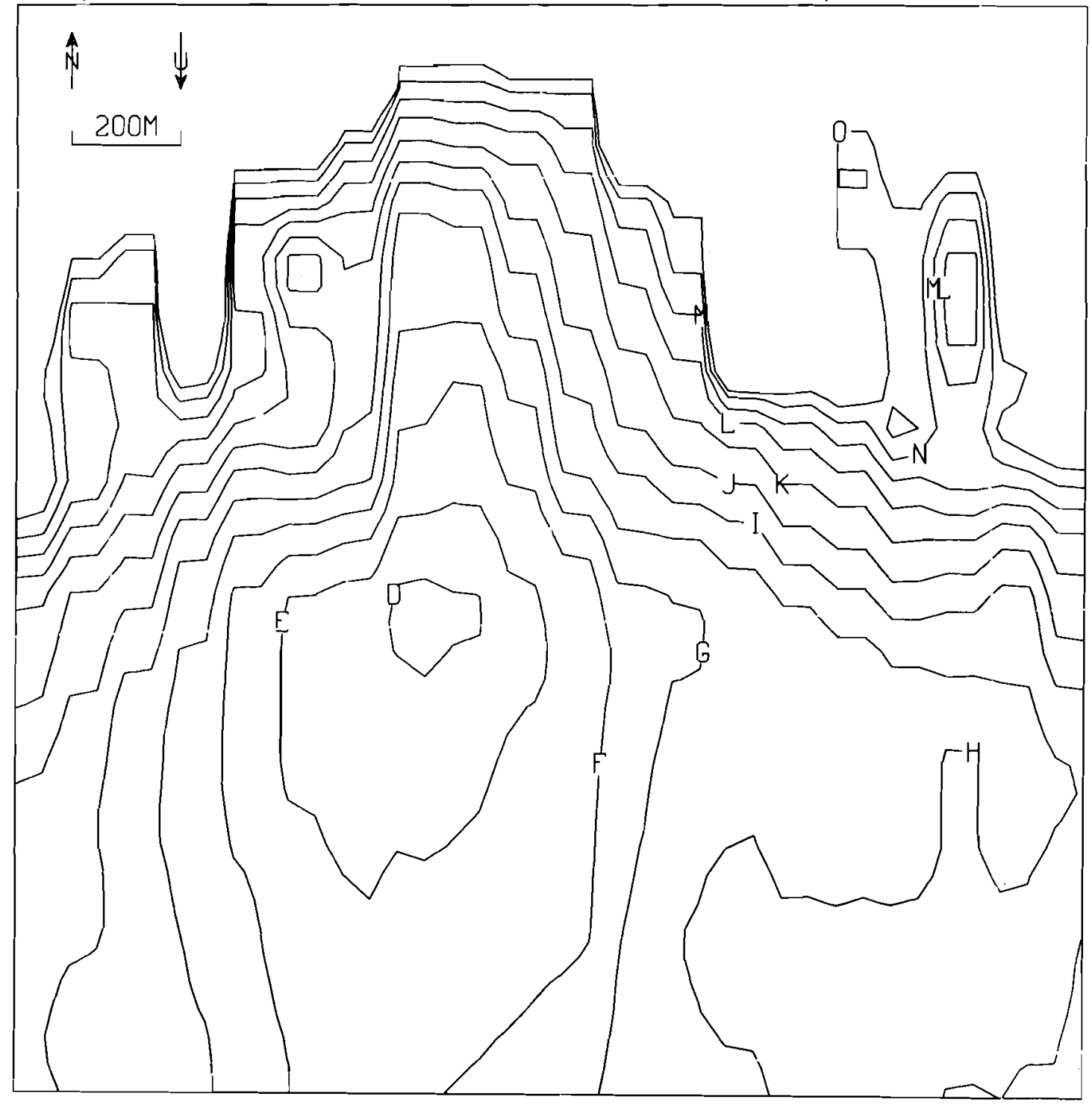

Figure 8. Contours of Normalized Suspended Air Concentration $\mathrm{uC} / \Lambda$ in the $\mathrm{BC}$ Controlled Area for Pasquill D, $v_{d} / u=0$, and a North Wind 
UC $\wedge$, RESSUSPENSION FROM BC CRIB RREA. PRSOUILL $D, \quad V D / U=0.0$

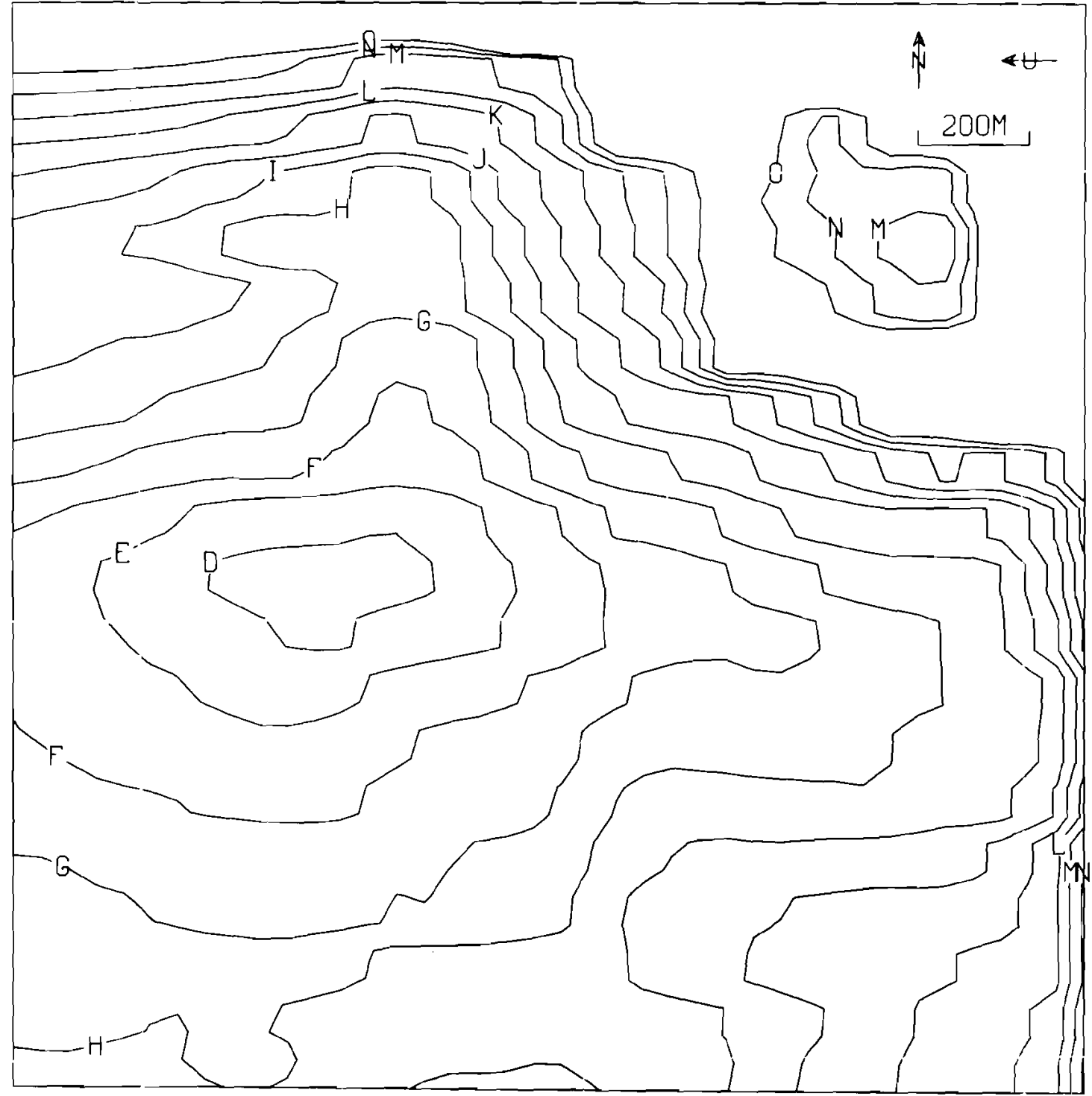

Figure 9. Contours of Normalized Suspended Air Concentration $\mathrm{uC} / \Lambda$ in the $B C$ Controlled Area for Pasquill $D$, $v_{d} / u=0$, and an East Wind 


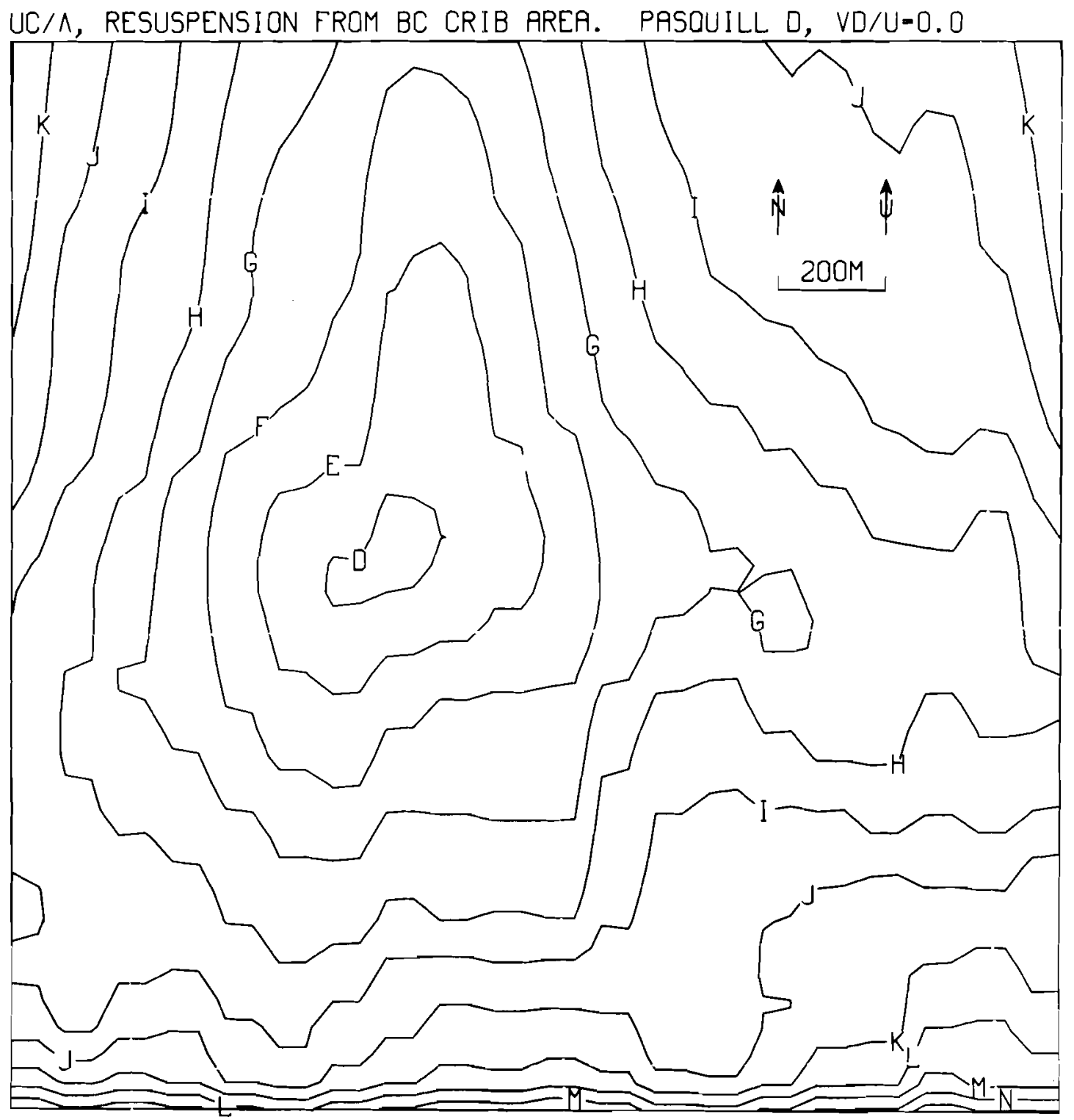

Figure 10. Contours of Normalized Suspended Air Concentration $\mathrm{uC} / \Lambda$ in the $\mathrm{BC}$ Controlled Area for Pasquill $\mathrm{D}$, $\mathrm{v}_{\mathrm{d}} / \mathrm{u}=0$, and a South Wind 
of deposition velocity $v_{d}$ to mean wind speed $u$ and results are shown for $v_{d} / u=0,10^{-3}, 10^{-2}$, and $10^{-1}$. Actually this largest value of $v_{d} / u$ is near the limit of applicability of the model since it implies deposition velocities of $10 \mathrm{~cm} / \mathrm{sec}$ or greater. If this large $v_{d}$ is due to gravitational settling, the particles are larger than $10 \mu \mathrm{m}$ diameter and are approaching the size at which they will no longer follow exactly the eddy motion of the atmosphere. This is contrary to one of the assumptions upon which the Gaussian plume model and Table 1 are based. Figure 7 is included, however, to emphasize the effects of deposition.

Increasing deposition affects the suspended air concentrations in a manner qualitatively similar to decreasing the atmospheric stability: $\mathrm{uC} / \Lambda$ is decreased and the downwind elongation of the air concentration contours is reduced. There is little change between $v_{d} / u=0$ and $v_{\mathrm{d}} / \mathrm{u}=10^{-3}$, but for $\mathrm{v}_{\mathrm{d}} / \mathrm{u}=10^{-2}$ the air concentration is reduced by about $35 \%$ at the peak and by about $60 \%$ at the east edge. For $v_{d} / u=10^{-1}$ the downwind elongation of the contours is reduced enough that Figure 7 duplicates quite closely the surface contamination pattern of Figure 1 .

Figures 3 and 8-10 display the effect of a changing wind direction on the suspended air concentration. Pasquill D is used for this, and the preceding comparison, for two reasons. First, representing the neutral stability condition, it is the "average" stability. Second, since high winds produce neutral stability the highest resuspension will occur under Pasquill D. A deposition velocity of zero is chosen to maximize the suspended air concentration.

Little of a general nature can be noted in Figures 3, 8-10 besides the obvious. The peak air concentration is little changed with wind direction but the contour pattern is highly altered, being elongated in the direction of the wind and producing air concentrations downwind of the peak an order of magnitude or more greater than those computed at the same location for other wind directions.

These sample concentrations demonstrate the dependence of the suspended air concentration on the relevant meteorological variables. 
This mociel can now be applied to the evaluation of the airborne hazards associated with the $\mathrm{BC}$ Controlled Area and to the further investigation of resuspension. Calculations should be made of the expected annual exposure within the BC Controlled Area and of the annual flux of contaminant out of the area, using the climatological distributions of stability, wind speed and wind direction. Isopleths of the maximum expected air concentration could also be calculated. Further, predictions of the model should be compared to existing measurements of airborne contamination within the area, both to test and improve the model and also to estimate the rate of suspension and the fraction of the surface contamination available for suspension.

\section{A Simplified Prediction Method}

\section{$\underline{\text { Model Derivation }}$}

The exact evaluation of (6) to predict the suspended air concentration is a tedious procedure because it requires the convolution of the areal source strength distribution with the point source function (1) describing the atmospheric dilution of the suspended contamination. Therefore, a simplified procedure has been developed which gives highly accurate results in the immediate vicinity of the area source, where the air concentrations are greatest. This method is derived in this section and its predictions are compared with those of (6) in the following sections.

The first step in simplifying (6) is to temporarily limit consideration to the crosswind-integrated air concentration

$$
C(x, z)=\int_{0}^{x}\left[\Lambda G(\xi)-v_{d} C\left(\xi, z_{d}\right)\right] \frac{D}{u}(x-\xi, z) d \xi,
$$

which was obtained by first integrating both sides of (6) over all y and then also performing the indicated integration over $\eta$. Thus, $G$ and $D$ are also now the crosswind-integrated values. Equivalently, (7) describes the air concentration resulting from a source which is uniform in the crosswind direction. Defining now a normalized air concentration 


$$
\psi \equiv \mathrm{uC} / \Lambda \mathrm{G},
$$

(7) becomes

$$
\psi(x, z)=\int_{0}^{x} \frac{G(\xi)}{G(x)}\left[1-\frac{v_{d}}{u} \psi\left(\xi, z_{d}\right)\right] D(x-\xi, z) d \xi .
$$

It is convenient to consider initially the situation $G=$ constant, in which case the first term on the right-hand side of (9) is

$$
\int_{0}^{\mathrm{x}} \mathrm{D}(\mathrm{x}-\xi, z) \mathrm{d} \xi=\int_{0}^{\mathrm{x}} \mathrm{D}(\zeta, z) \mathrm{d} \zeta \equiv \psi_{0}(x, z),
$$

the normalized air concentration from a uniform area source of nondepositing material extending a distance $x$ upwind of the receptor. $\psi_{0}$ has been calculated at a height of $1 \mathrm{~m}$ using the rural diffusion parameters of Briggs. The results for Pasquill stability categories A, D and F are shown by the solid curves of Figure 11. As would be expected, the air concentrations increase with distance from the upwind edge of the source. They increase least rapidly in the case of an unstable thermal stratification (Pasquill A) due to the enhanced effectiveness of the vertical mixing in transporting the material away from the surface; most rapidly in the case of a stable atmosphere (Pasquill F) due to the suppression of the vertical mixing. This is similar to the effects of stability noted in the examples of the previous section.

Looking next at the second term on the right-hand side of (9), still for the case of a uniform surface contamination, it can be concluded that its contribution to the integrand is maximized near $\xi=\mathrm{x}$. This is based on two observations. First, $\psi_{0}$ (and also $\psi$ as will be seen presently) increases monotonically with downwind distance. Secondly, $D(x-\xi, z)$ has a maximum in the vicinity of $\xi=\mathrm{x}$ which becomes narrower and closer to $\xi=x$ as $z$ approaches zero. Thus it is a good approximation (best for small $z$ and when $\psi$ changes slowly with $x)$ to replace $\psi\left(\xi, z_{d}\right)$ in the integrand with $\psi\left(x, z_{d}\right)$, giving

$$
\psi(\mathrm{x}, \mathrm{z}) \approx\left[1-\frac{\mathrm{v}_{\mathrm{d}}}{\mathrm{u}} \psi\left(\mathrm{x}, \mathrm{z}_{\mathrm{d}}\right)\right] \psi_{\mathrm{o}}(\mathrm{x}, \mathrm{z}) .
$$




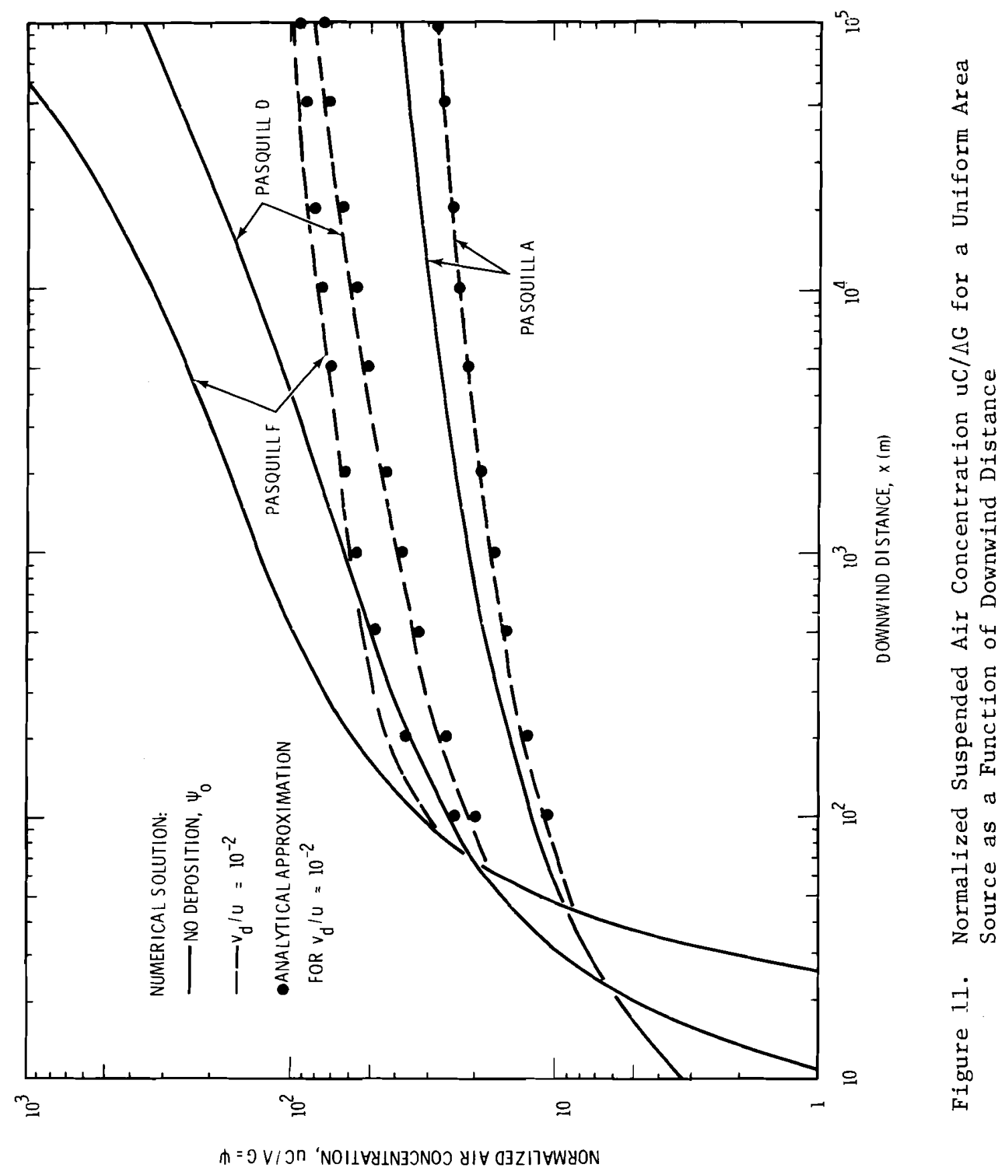


Solving for $\psi(x, z)$

$$
\psi(x, z) \approx \psi_{0}(x, z) /\left[1+\frac{v_{d}}{u} \psi_{0}\left(x, z_{d}\right)\right] \quad .
$$

The predictions of (12) for the normalized air concentration due to a uniform area source of depositing contaminant are shown as discrete data points in Figure 11 for $\mathrm{v}_{\mathrm{d}} / \mathrm{u}=10^{-2}$, a case of moderately strong deposition, and for $z_{d}=1 \mathrm{~m}$. Also shown as dashed lines are the exact solutions calculated with (9). Equation (12) is quite adequate for all these conditions and is actually in error by less than $10 \%$ over most of the range shown. As would be predicted from the slope of the $\psi$ curves, the agreement is best for Pasquill $\mathrm{A}$ and large $\mathrm{x}$ and worst for Pasquill $\mathrm{F}$ and small $\mathrm{x}$. The small slope of the $\psi$ curves at large $\mathrm{x}$, particularly for Pasquill D and $F$, is due to their approach to the asymptotic limit $\mathrm{u} / \mathrm{v}_{\mathrm{d}}$. This limit can be predicted either from (12) or directly from (9) and reflects an exact balance between resuspension and deposition.

The approximation (11) is still valid if $G(x)$ is allowed to be a monotonically increasing function of $x$. Thus

$$
\psi(x, z)=\left[1-\frac{v_{d}}{u} \psi\left(x, z_{d}\right)\right] \int_{0}^{x_{G}(\xi)} \frac{G(x)}{G(x-\xi, z) d \xi} .
$$

The remaining integral can be further reduced by changing the variable of integration to

$$
d \xi^{*}=\frac{G(\xi)}{G(x)} d \xi
$$

whence it becomes

$$
\int_{0}^{x^{*}} D(x-\xi, z) d \xi^{*}
$$

Here $x^{*}$ is a scaled distance

$$
x^{*}=\int_{0}^{x_{G}} \frac{G(\xi)}{G(x)} d \xi
$$


Now, it is apparent that (15) is closely related to

$$
\psi_{0}\left(x^{*}, z\right)=\int_{0}^{x^{*}} D\left(x^{*}-\xi^{*}, z\right) d \xi^{*},
$$

and to investigate this relationship we can examine

$$
x^{*}-\xi^{*}=\int_{\xi}^{x_{G}} \frac{G(\zeta)}{G(x)} d \zeta
$$

In the vicinity of $\xi=x, G(\zeta) \simeq G(x)$ and hence $x^{*}-\xi^{*} \simeq x-\zeta$. But ic is in just this region where $D(x-\xi, z)$ makes its greatest contribution to the integral in (15) or (17). Thus to a good approximation (again best for small $\mathrm{z}$ and slowly increasing G) (13) becomes

$$
\psi(\mathrm{x}, \mathrm{z}) \simeq\left[1-\frac{\mathrm{v}_{\mathrm{d}}}{\mathrm{u}} \psi\left(\mathrm{x}, \mathrm{z}_{\mathrm{d}}\right)\right] \psi_{\mathrm{o}}\left(\mathrm{x}^{*}, \mathrm{z}\right),
$$

and, after solving for $\psi(x, z)$,

$$
\psi(x, z) \simeq \psi_{0}\left(x^{*}, z\right) /\left[1+\frac{v_{d}}{u} \psi_{0}\left(x^{*}, z_{d}\right)\right] .
$$

Finally, it is necessary to lift the restrictions on $G$ altogether. This is easily accomplished by again utilizing the principle of linear superposition of solutions and dividing the surface contamination into a number of segments, each of which is monotonically increasing in the downwind direction. If $G(x)$ has a peak at $x=x_{0}$, we can define

$$
G_{1}(x)= \begin{cases}G(x), & x<x_{0} \\ G\left(x_{0}\right), & x>x_{0}\end{cases}
$$

and

$$
G_{2}(x)=\left\{\begin{array}{cl}
0 & , \quad x<x_{0}^{0} \\
G\left(x_{0}\right)-G(x), & x>x_{0}
\end{array}\right.
$$

both of which are monotonically increasing functions of $x$ and the difference of which is equal to $G(x)$. Applying (20),

$$
C(x, z)=\frac{\Lambda}{u}\left\{\frac{G_{1}(x) \psi_{o}\left(x_{1}^{*}, z\right)}{1+\frac{v_{d}}{u} \psi_{o}\left(x_{1}^{*}, z_{d}\right)}-\frac{G_{2}(x) \psi_{o}\left(x_{2}^{*}, z\right)}{1+\frac{v_{d}}{u} \psi_{o}\left(x_{2}^{*}, z_{d}\right)}\right\} .
$$


Using (23) the crosswind-integrated air concentration of resuspended material may be predicted for any area source by evaluating $\psi_{0}$ at the scaled distance $x^{*}$. Deposition is accounted for in the simple manner derived for a uniform area source. Note especially that the tedious convolution integral (9) has been replaced by the simpler integrals (10) and (16). $\psi_{0}$ of course need only be calculated once for each choice of the diffusion function D. Finally, it will be shown later that the application of (23) is not limited to the crosswind-integrated value of $\mathrm{C}$.

\section{Comparison with the Exact Solution}

The accuracy of the air concentrations estimated by (23) may be tested by comparison with the direct predictions of the basic equation (6). Two distributions of surface contamination were used for this test: a Gaussian

$$
G=G_{0} \exp \left[-\frac{\left(x-x_{0}\right)}{2 \sigma_{1}^{2}}-\frac{y^{2}}{2 \sigma_{2}^{2}}\right] \text {, }
$$

selected as a general representation of surface contamination, and the $B C$ Controlled Area. Distributions of the air concentrations of suspended material were calculated by numerically solving the basic equation (6), as was done previously, and also by applying the analytical approximation (23) with the $\psi_{0}$ curves of Figure 11.

Figure 12 shows the predicted crosswind-integrated air concentrations, normalized by $\sqrt{2 \pi} \sigma_{2} \Lambda G_{o} / \mathrm{u}$, for the Gaussian source with $\sigma_{1}=10^{3} \mathrm{~m}$ and Pasquill D. The solution of (6) is given by the solid curve for no deposition and by the broken curve for $v_{d} / u=10^{-2}$. The dotted line simply shows the shape of the crosswind-integrated surface contamination distribution. The predictions of (23) are plotted as discrete data points and can be seen to agree with the exact solution within $10 \%$ to $20 \%$. The agreement between the two solutions changes little with atmospheric stability, being slightly better for Pasquill A and slightly worse for Pasquill $F$ as could be predicted from the derivation of (20). The agreement is degraded by about an additional $5 \%$ when $\sigma_{1}$ is reduced to 


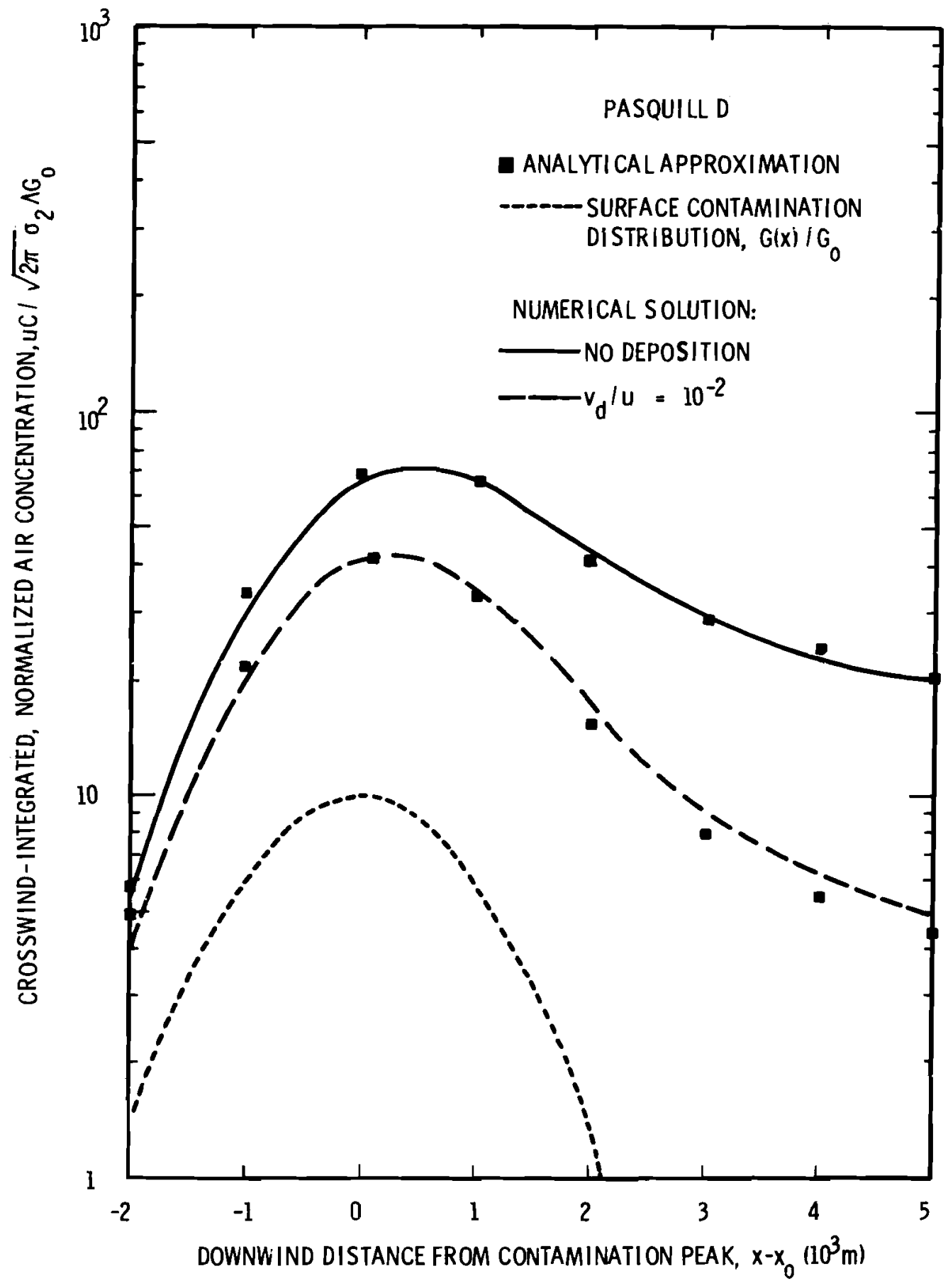

Figure 12. Comparison of Suspension-Deposition Models for a Crosswind-Integrated Gaussian Area Source 


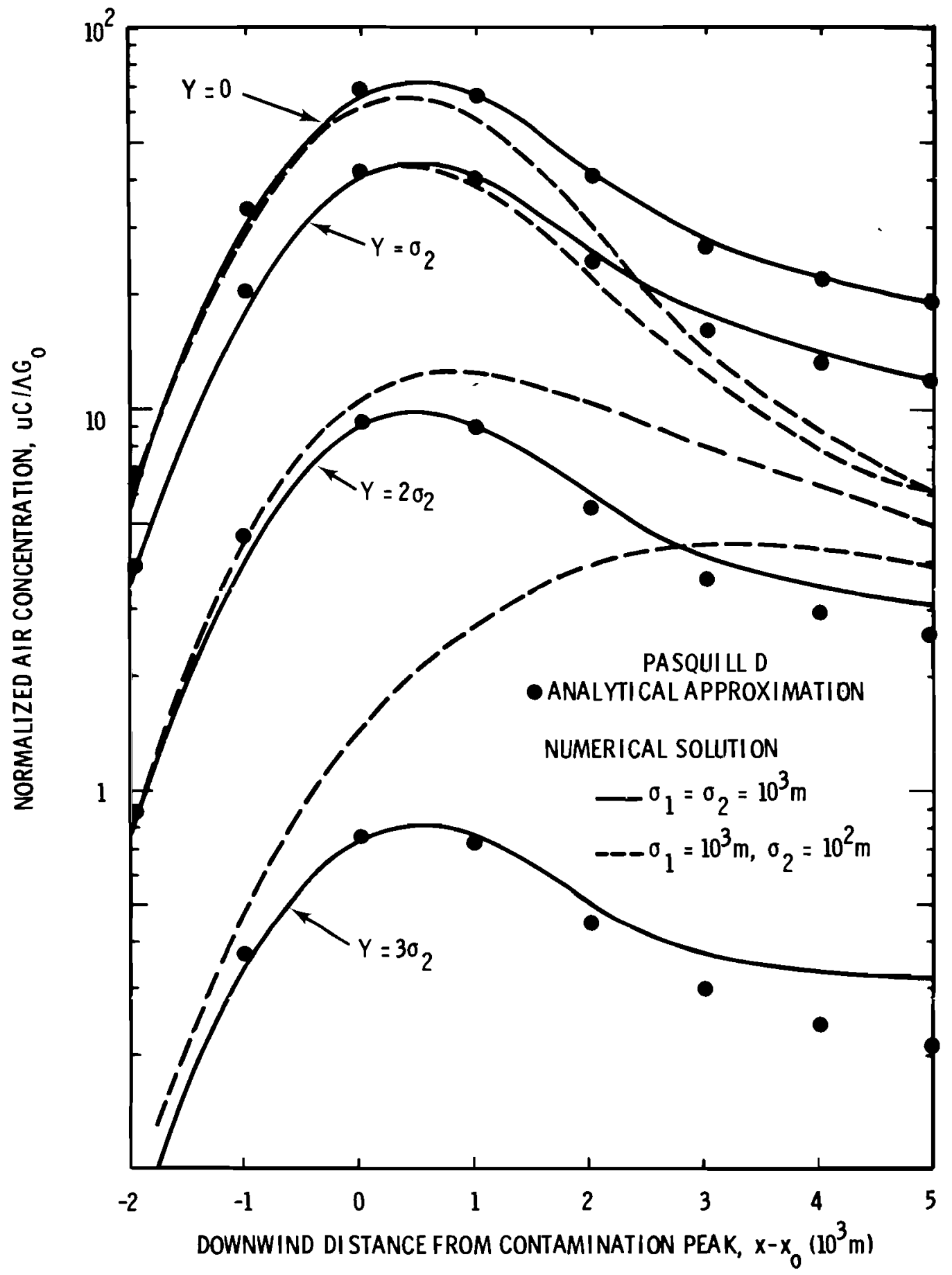

Figure 14. Comparison of Suspension Models for Gaussian Sources and Pasquill D Stability Category 
the peak and at distances of one, two and three standard deviations crosswind of the peak. Also shown as discrete points are the predictions of (23), based on the surface contamination distribution directly upwind of the receptor. This is equivalent to assuming that the crosswind distribution is uniform at that value. From the results it can be seen that for $\sigma_{2}$ also equal to $10^{3} \mathrm{~m}$ this is a good approximation, especially upwind of and directly downwind of the peak. As $\sigma_{2}$ increases above $10^{3} \mathrm{~m}$, the air concentrations at crosswind distances of two and three times $\sigma_{2}$ approach the close match with the predictions of (23) displayed in Figure 14 at $y=0$. On the other hand as $\sigma_{2}$ decreases, producing a narrow surface distribution in the crosswind direction, the agreement deteriorates. This is exemplified by the dashed curves for $\sigma_{2}=10^{2} \mathrm{~m}$. The approximation is still good upwind of the peak, but deteriorates rapidly downwind of the peak. In the latter case a point source solution would more closely approximate the observed distribution.

Since the predictions of (23) in Figure 14 are based on the surface contamination distribution directly upwind of the receptor, the agreement with the air concentration as calculated from the basic equation (6) depends on the effectiveness of the crosswind diffusion. The least lateral diffusion occurs for Pasquill F, Figure 15, and hence for $\sigma_{1}=\sigma_{2}=10^{3} \mathrm{~m}$ the air concentrations at crosswind distances of two and three times $\sigma_{2}$ match the predictions almost as well as for $\mathrm{y}=0$. There is also a modest improvement from Pasquill $\mathrm{D}$ in the match for $\sigma_{2}=10^{2} \mathrm{~m}$, especially for $\mathrm{y}=0$ and $\mathrm{y}=\sigma_{2}$. On the other hand the match for Pasquill A, Figure 16, and $\sigma_{1}=\sigma_{2}=10^{3} \mathrm{~m}$ is considerably poorer at $\mathrm{y}=2 \sigma_{2}$ and $\mathrm{y}=3 \sigma_{2}$ than that for Pasquill D. Calculations were also made for $\sigma_{1}=10^{2} \mathrm{~m}, \sigma_{2}=10^{2} \mathrm{~m}$ and $\sigma_{2}=10 \mathrm{~m}$ and the predictions of (23) matched those of (6) in the same manner as the results for $\sigma_{1}=10^{3} \mathrm{~m}$, $\sigma_{2}=10^{3} \mathrm{~m}$ and $\sigma_{2}=10^{2} \mathrm{~m}$.

In summary, the Gaussian distributions of surface contamination demonstrate that (23) is adequate to predict the resuspended air concentrations, based only on the contamination directly upwind of the receptor, to within several tens of percent if the distribution has 


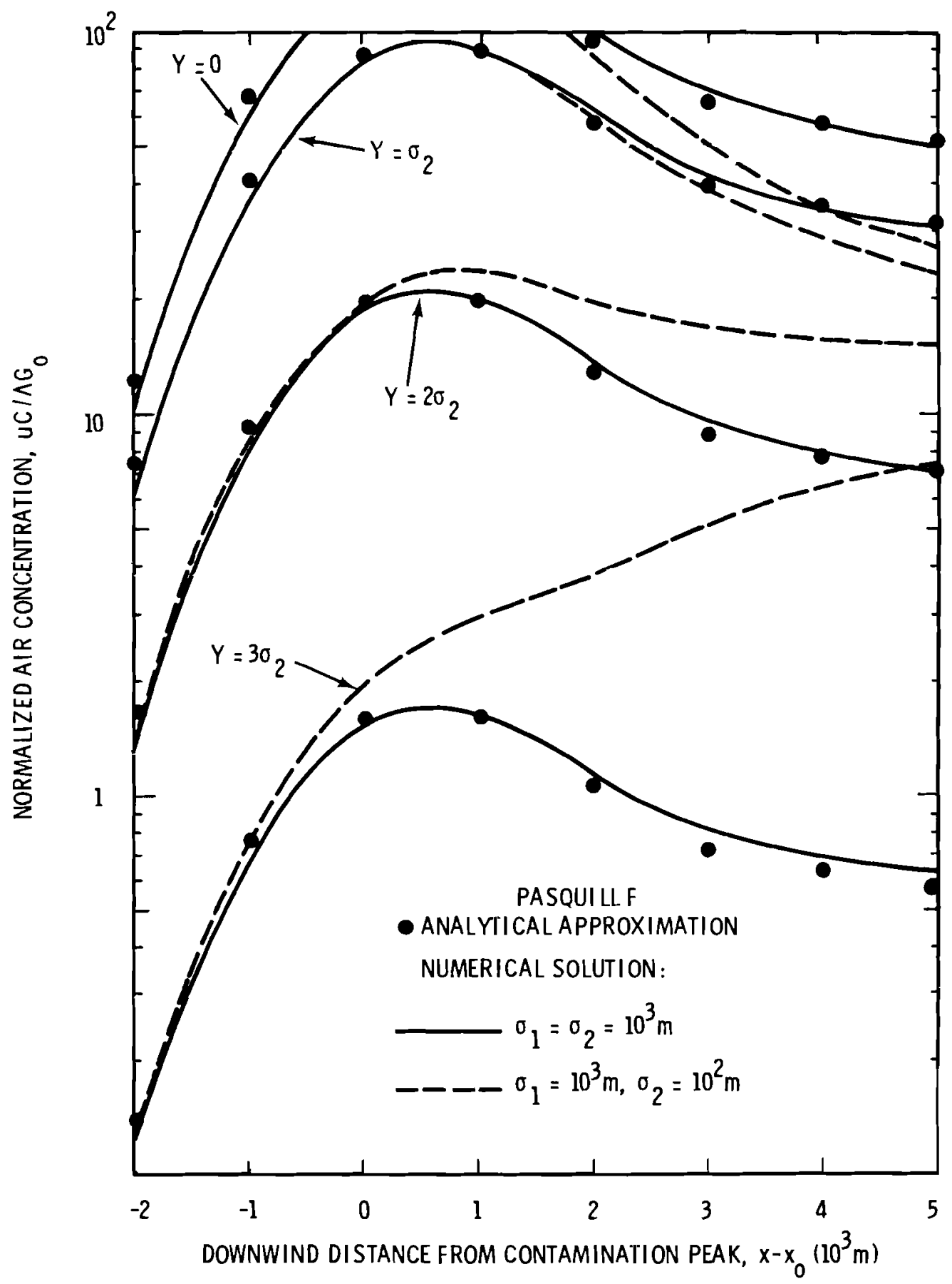

Figure 15. Comparison of Suspension Models for Gaussian Sources and Pasquill F Stability Category 


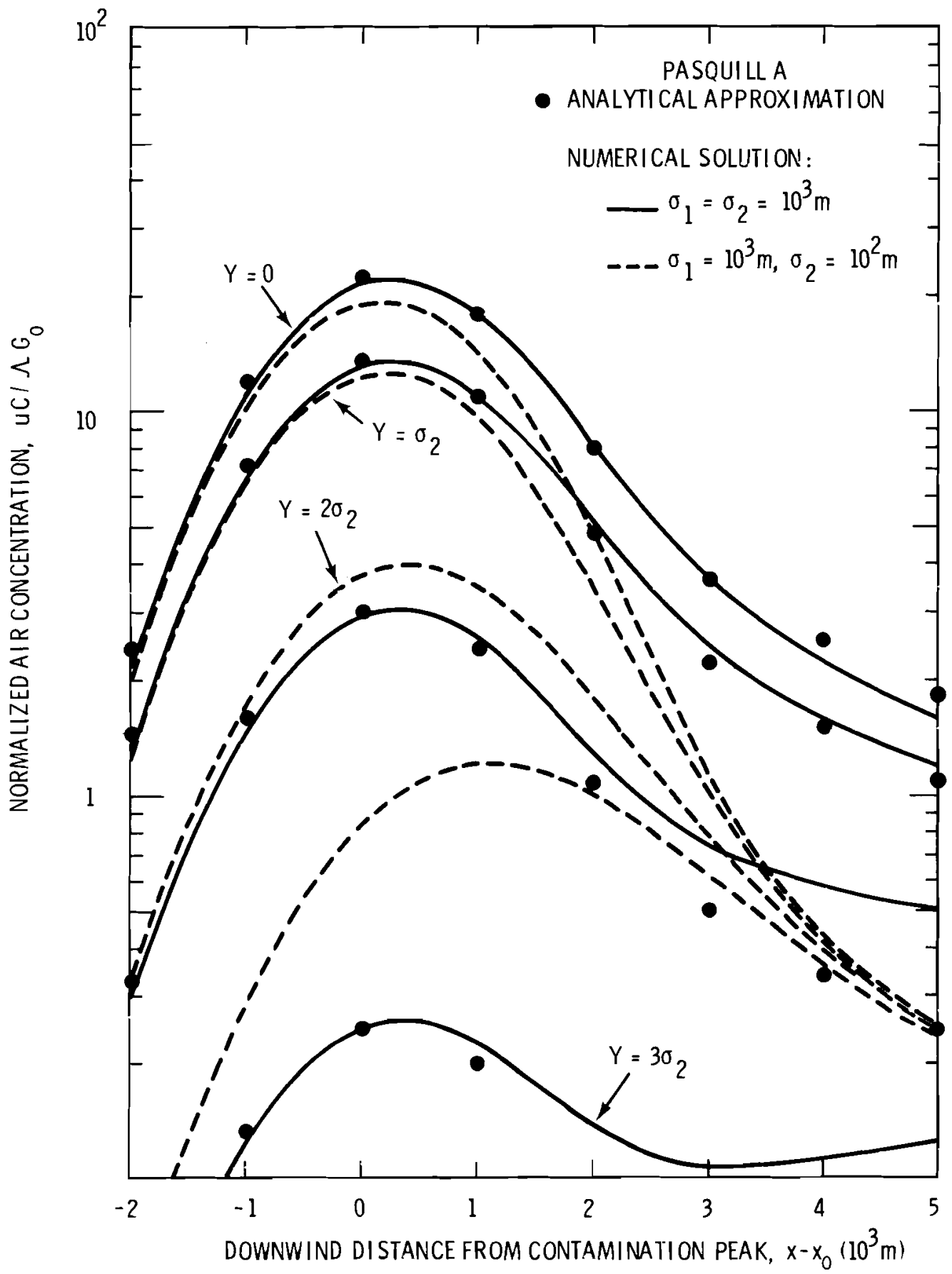

Figure 16. Comparison of Suspension Models for Gaussian Sources and Pasquill A Stability Category 
roughly the same extent in all directions. The peak air concentration is predicted with an error of less than $10 \%$, and the percent errors increase with increasing distance from the peak of the surface distribution. However, the air concentration is at the same time decreasing with distance from the peak. The error may be greater than a factor of two beyond a distance of about three standard deviations from the peak, especially for unstable atmospheric conditions, but where this occurs the air concentration is usually less than $10 \%$ of the peak concentration. The effect of deposition was not included in the calculations for the Gaussian sources, but the result would have been an enhancement of the predictive capability of (23).

Finally, Figure 17 shows the crosswind distribution of suspended air concentration for the BC Controlled Area, similarly calculated from both equations, at two downwind distances: $x=900 \mathrm{~m}$, the peak of the crosswind-integrated distribution, and $x=2000 \mathrm{~m}$, the downwind edge of the calculational area. The meteorological conditions are identical to those of Figures 6 and 13. At $900 \mathrm{~m}$ the predictions of (23), involving essentially only the first term of that equation, agree excellently with the numerical solution of (6). At $2000 \mathrm{~m}$ the agreement is poorer, within about $50 \%$ at worst, but in most cases within $15 \%$. Equation (23) underpredicts worst north of the peak because here $\mathrm{x}=2000 \mathrm{~m}$ is far downwind of all the directly upwind surface contamination but is on the north edge of the central contamination pattern (see Figures 1 and 14). Calculation of the Horizontal Flux

The total horizontal flux of contaminant (quantity per sec) in the downwind direction,

$$
F_{H} \equiv \int_{0}^{\infty} \int_{-\infty}^{\infty} u C(x, y, z) d y d z,
$$

may be found by substitution of (6) into (25) to be

$$
F_{H}=\int_{0}^{x}\left[\Lambda G(\xi)-v_{d} C\left(\xi, z_{d}\right)\right] d \xi \text {. }
$$




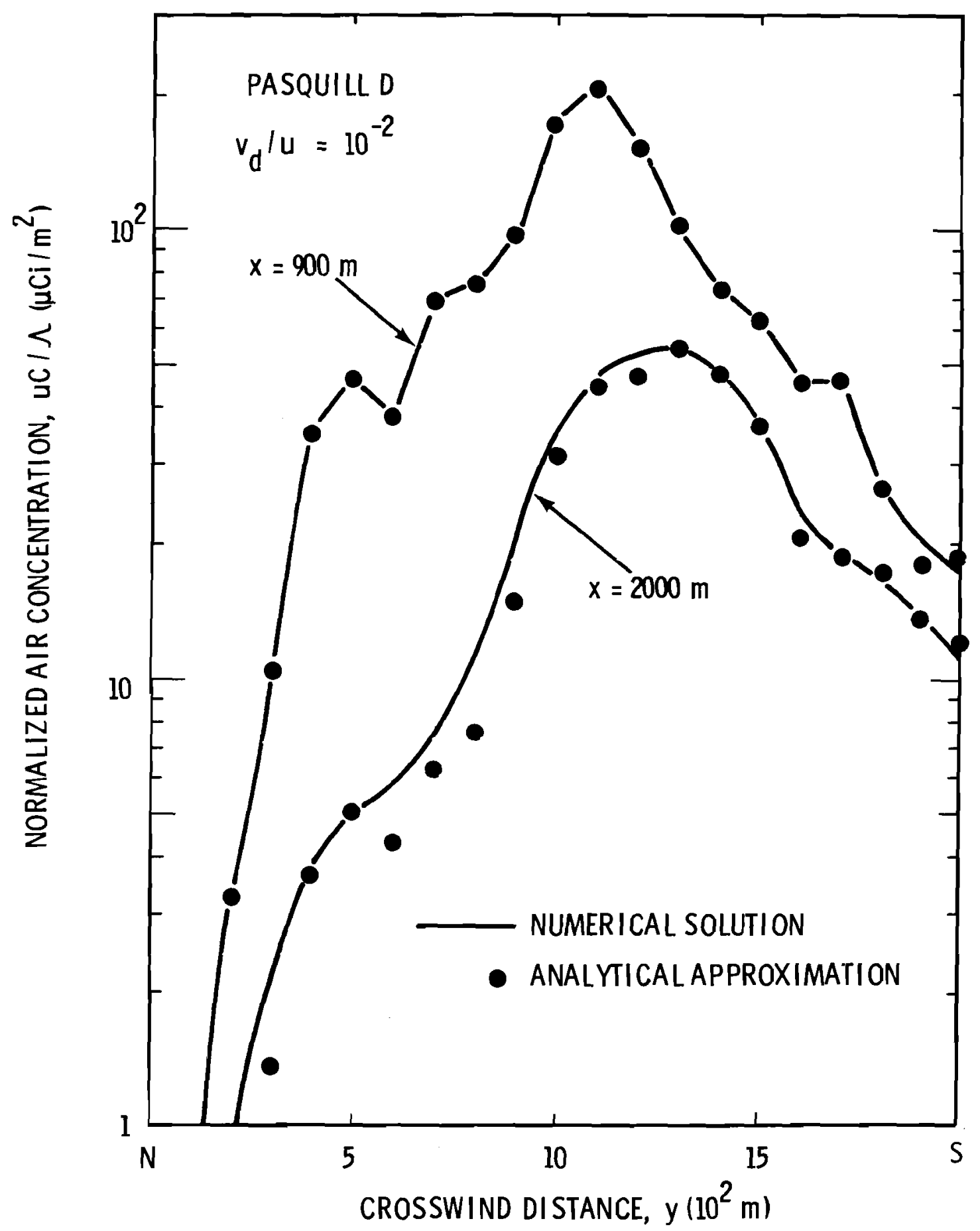

Figure 17. Comparison of Suspension-Deposition Models for the $\mathrm{BC}$ Controlled Area 
This is in fact simply a statement of conservation of material: the horizontal flux (25) is equal to the net vertical flux at the surface (26). An approximate value for $\mathrm{F}_{\mathrm{H}}$ may be obtained by substitution of (20) into (25),

$$
\mathrm{F}_{\mathrm{H}} \simeq \Lambda \mathrm{G}(\mathrm{x}) \int_{0}^{\infty} \psi_{\mathrm{o}}\left(\mathrm{x}^{*}, \mathrm{z}\right) \mathrm{dz} /\left[1+\frac{\mathrm{v}_{\mathrm{d}}}{\mathrm{u}} \psi_{\mathrm{o}}\left(\mathrm{x}^{*}, \mathrm{z}_{\mathrm{d}}\right)\right] .
$$

Recalling the definition (10) of $\psi_{0}$ and ( 1 ) for D, it is easily seen that

$$
\int_{0}^{\infty} \psi_{0}\left(x^{*}, z\right) d z=x^{*}
$$

and hence

$$
F_{H} \simeq \int_{0}^{x} \Lambda G(\xi) d \xi /\left[1+\frac{v_{d}}{u} \psi_{o}\left(x^{*}, z_{d}\right)\right] .
$$

Thus the horizontal flux is equal to the upwind suspension, appropriately reduced to account for deposition. The extension of (29) to the general source as evaluated with (21) - (23) is obviously

$$
\mathrm{F}_{\mathrm{H}}=\frac{\Lambda G_{1}(\mathrm{x}) \mathrm{x}_{1}^{*}}{1+\frac{\mathrm{v}_{\mathrm{d}}}{\mathrm{u}} \psi_{\mathrm{o}}\left(\mathrm{x}_{1}^{*}, \mathrm{z}_{\mathrm{d}}\right)}-\frac{\Lambda G_{2}(\mathrm{x}) \mathrm{x}_{2}^{*}}{1+\frac{\mathrm{v}_{\mathrm{d}}}{\mathrm{u}} \psi_{\mathrm{o}}\left(\mathrm{x}_{2}^{*}, \mathrm{z}_{\mathrm{d}}\right)}
$$

In deriving (29), (20) was assumed to be applicable at all heights whereas in fact it is best for small $z$. As $z$ increases, (20) increasingly overestimates the reduction of $\psi_{0}$ due to deposition and thus (29) underestimates the horizontal flux. However, due to the vertical distribution of $\psi_{0}$ the major contribution to $\mathrm{F}_{\mathrm{H}}$ is near $z=0$, i.e., the bulk of the flux is carried near the surface, and (29) is still a fairly good approximation. This may be seen in Figure 18 for a uniform area source and $v_{d} / u=10^{-2}$, where for Pasquill $F(29)$ is at worst in error by $30 \%$. Note also that (29) retains the property of (12) that the approximation deteriorates with increasing stability.

To illustrate the general case, (30) was applied to the BC Controlled Area for Pasquill D and $v_{d} / u=10^{-2}$. As seen in Figure 19, (30) 


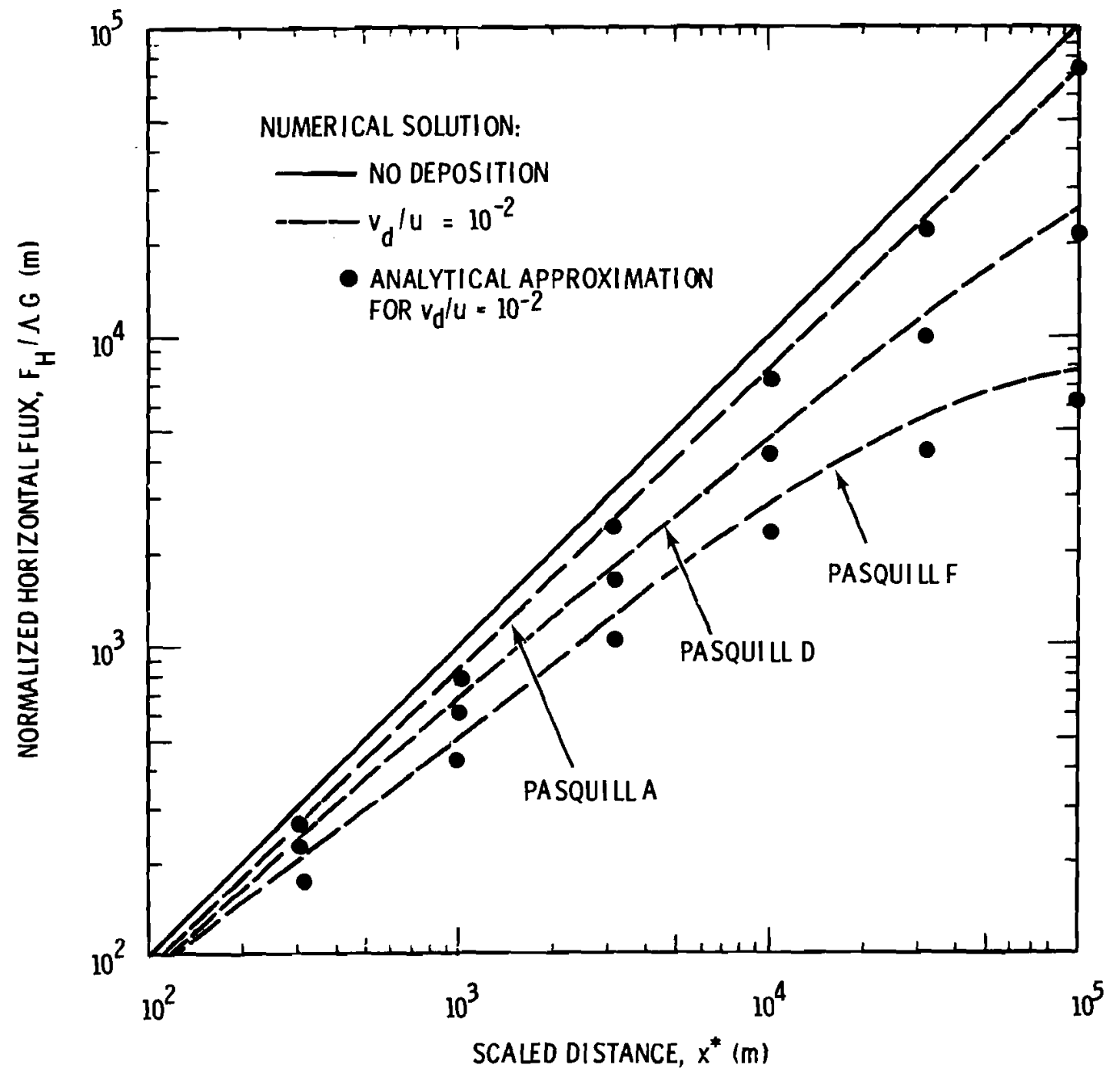

Figure 18. Normalized Horizontal Flux $F_{H} / \Lambda G$ for a Uniform Area Source as a Function of Downwind Distance 


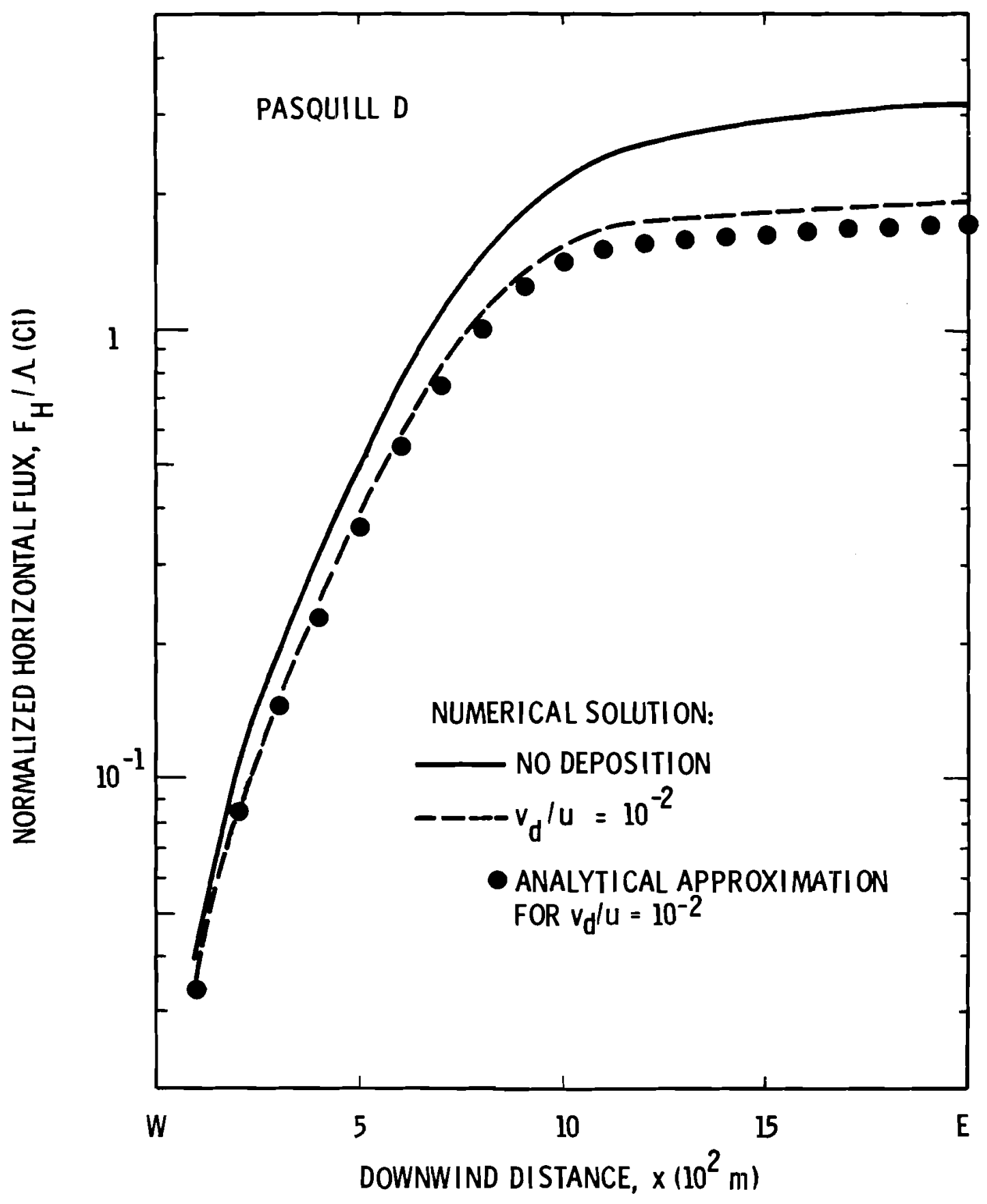

Figure 19. Normalized Horizontal Flux $\mathrm{F}_{\mathrm{H}} / \Lambda$ for the
$\mathrm{BC}$ Controlled Area 
underestimates the horizontal flux by about $15 \%$ at the eastern edge of the calculational area.

Usefulness of the Resuspension Factor

Faced with the need to estimate the hazard due to the suspension of surface contamination and lacking models such as that developed here, the nuclear industry has summarized its experience in terms of a resuspension factor ${ }^{(6)}$

$$
\mathrm{K} \equiv \mathrm{C} / \mathrm{G} \quad \text {. }
$$

The limited data from incidents of radioactive surface contamination appear to indicate (7) a value of $10^{-6}$ to $10^{-5} \mathrm{~m}^{-1}$ for freshly deposited material resuspended by natural processes. Recent controlled experiments ${ }^{(3)}$ with a nonradioactive tracer indicate a lower value of $10^{-10}$ to $10^{-9} \mathrm{~m}^{-1}$.

The resuspension factor, however, does not account for the variations in $C$ due to source configuration nor for the dependence of diffusion on source-receptor separation. Hence, measured values of $\mathrm{K}$ can be used with confidence to estimate $C$ in new situations only when $K$ is known to vary little with location relative to the contamination distribution. The results developed in previous sections of this report can be used to delineate those situations.

In Figure 12 the resuspension factor is proportional to the ratio of the air concentration curves to the surface contamination curve, and hence also to their vertical separation. $\mathrm{K}$ may be seen to increase slowly with $x$ upwind of the peak and then more rapidly downwind of the peak. In general the resuspension factor has little usefulness downwind of a contaminated area because $\mathrm{C}$ is controlled by the upwind contamination rather than the rapidly decreasing local contamination. This may be one reason why the earlier values for $K$ exceed those recently measured within a uniformly contaminated area. Note also that the inclusion of deposition in Figure 12 increases the linkage of $\mathrm{C}$ with the local value of $G$, decreasing the variation of $K$ with location. A large deposition velocity decreases the downwind influence of the 
surface contamination on the air concentration. Recall from the earlier discussion of suspension from the BC Controlled Area that decreasing the atmospheric stability has the same effect.

Equation (20) directly predicts the value of $K$ upwind of the contamination peak. Figure 11 shows $k$, in units of $\Lambda / u$, at the deposition reference height of $1 \mathrm{~m}$. For $\mathrm{x}^{*} \approx 100 \mathrm{~m}, \mathrm{~K}$ increases rapidly with $\mathrm{x}^{*}$; between $100 \mathrm{~m}$ and $10 \mathrm{~km}, \mathrm{~K}_{\mathrm{O}}$ (without deposition) increases least rapidly; and beyond $10 \mathrm{~km} \mathrm{~K}$ begins to increase more rapidly again as the vertical mixing reaches a limiting value, especially for the stable Pasquill F. Once more it is apparent that the resuspension factor varies least with location for unstable atmospheric conditions and strong deposition. From (20) it can be seen that at large $x^{*} \mathrm{~K}$ with deposition approaches the limiting value $\Lambda / v_{d}$. 


\section{ACKNOWLEDGMENTS}

The thoughtful interest and helpful suggestions of W.G.N. Slinn were especially appreciated during the development of the simplified model presented here.

This report presents the results of research supported both by the Atlantic Richfield Hanford Company, under contract to the U.S. Energy Research and Development Administration, and by the Department of Biomedical and Environmental Research of the U.S. Energy Research and Development Administration. 


\section{REFERENCES}

1. F. Pasquill, Atmospheric Diffusion, Halsted Press, New York, NY, p. 352,1974 .

2. G. A. Sehmel and W. H. Hodgson, "Predicted Dry Deposition Velocities," Proceedings of Atmosphere-Surface Exchange of Particulate and Gaseous Pollutants - 1974 Symposium, Richland, WA, September 4-6, 1974, CONF-740921, ERDA Symposium Series 38, ERDA Technical Information Center, Oak Ridge, TN, January 1976.

3. G. A. Sehmel and F. D. Lloyd, "Initial Particle Resuspension Rates A Field Experiment Using Tracer Particles," Pacific Northwest Laboratory Annual Report for 1974 to the USAEC Division of Biomedical and Environmental Research, Part 3, Atmospheric Sciences, BNWL-1950, Pt. 3, Battelle, Pacific Northwest Laboratories, Richland, WA, February 1975.

4. G. A. Briggs, Diffusion Estimation for Small Emissions, ATDL Contribution 79, Air Resources Atmospheric Turbulence and Diffusion Laboratory, Oak Ridge, TN, 1973.

5. L. E. Bruns, "Aerial Gamma Survey by Helicopter to Measure Surficial Contamination," Proceedings of Atmosphere-Surface Exchange of Particulate and Gaseous Pollutants - 1974 Symposium, Richland, WA, September 4-6, 1974, CONF-740921, ERDA Sympcsium Series 38, ERDA Technical Information Center, Oak Ridge, TN, January 1976.

6. K. Stewart, "The Resuspension of Particulate Material from Surfaces," Surface Contamination, B. R. Fish, Editor, Pergamon Press, New York, NY, 1967.

7. J. Mishima, A Review of Research on Plutonium Releases During Overheating and Fires, HW-83668, Hanford Laboratories, General Electric Co., Richland, WA, 1964. 
BNWL-2047

UC-11

No. of

Copies

Off-Site

1 ERDA Chicago Patent Group 9800 South Cass Avenue Argonne, IL 60439

A. A. Churm

5 ERDA Division of Biomedical and Environmental Research Washington, DC 20545

D. H. Slade

R. W. Beadle

D. S. Ballantine

N. F. Barr

$\mathrm{H}$. Moses

2 ERDA Division of Nuclear Fuel Cycle and Production Washington, DC 20545

F. P. Baranowski

W. K. Eister

2 NRC Division of Research Washington, DC 20555

J. J. Davis

H. Landon

$1 \quad$ Norfolk State College

Mathematics Department 2401 Corprew Avenue Norfolk, VA 23504

A. J. Amato

2 NOAA Atmospheric Turbulence and Diffusion Laboratory P. O. Box E

Oak Ridge, TN 37830

F. Gifford

S. R. Hanna
No. of

Copies

Off-Site

2 Los Alamos Scientific Laboratory of the University of California Los Alamos, NM 87544

J. W. Healy

J. R. Travis

1 University of Idaho College of Forestry Wildlife and Range Sciences Moscow, ID 83843

G. H. Belt

1 AAEC Research Establishment Private Mail Bag Sutherland 2232

N.S.W. Australia

G. H. Clark

200 ERDA Technical Information Center

On-Site

5 ERDA Richland Operations Office

P. F. X. Dunigan

R. B. Goranson

N. T. Karagianes

B. J, Melton

J. L. Rhoades 
No. of

Copies

On-Site

$\underline{\text { On-Site }}$

31 Atlantic Richfield Hanford

Battelle-Northwest (cont.)

Company

W. G. N. Slinn

H. Babad

D. J. Brown (10)

L. E. Bruns

T. H. Smith

E. C. Watson

L. L. Wendell

G. E. Buckman

G. Burton

R. A. Deju

E. R. Dornheim

R. D. Fox

R. E. Isaacson

C. Klingsberg

E. J. Kosiancic

M. W. Legatski

B. J. McMurray

D. L. Merrick

G. C. Owens

J. V. Panesko

W. H. Price

R. C. Roal

H. P. Shaw

J. A. Teal

J. H. Warren

A. T. White

\section{Battelle-Northwest}

T. I. Bander

R. L. Drake

J. G. Droppo

C. E. Elderkin

J. M. Hales

T. W. Horst (25)

J. Mishima

P. W. Nickola

M. M. Orgill

D. C. Powell

J. V. Ramsdell

W. F. Sandusky

L. C. Schwendiman

G. A. Sehmel

C. L. Simpson

W. K. Winegardner

M. A. Wolf

Technical Information Files (3)

Technical Publications (1) 